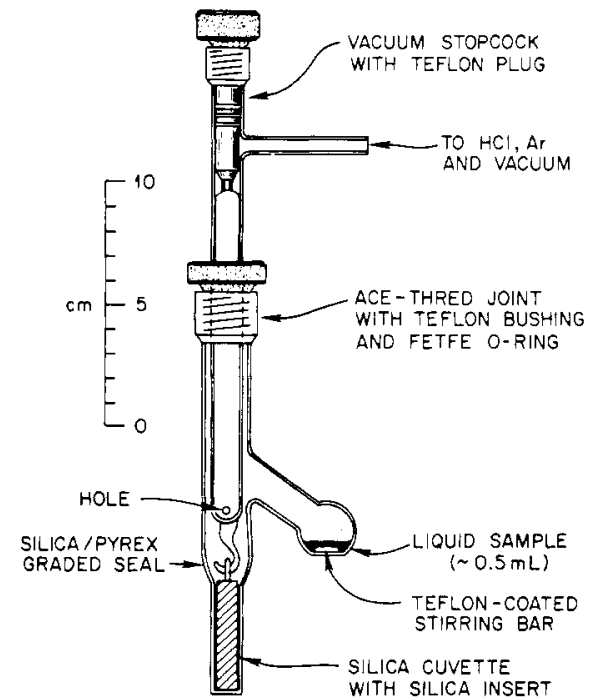

Figure 6. Protonation cell.

consisting first of anhydrous $\mathrm{CaSO}_{4}$, then reduced copper oxide wire at $270^{\circ} \mathrm{C}$, and finally anhydrous $\mathrm{Mg}\left(\mathrm{ClO}_{4}\right)_{2}$. High-purity Ar was further treated by passing through a train consisting first of anhydrous $\mathrm{Mg}$ $\left(\mathrm{ClO}_{4}\right)_{2}$ and then reduced copper oxide wire at $315^{\circ} \mathrm{C}$. Once the cell was fastened to the manometric apparatus, the connecting arm was evacuated and the cell slowly opened to a vacuum. Care had to be taken here because the stirred molten salt solution tended to froth. Once the frothing had subsided and the pressure at the pump reduced to less than $10^{-5} \mathrm{~atm}$, the cell was isolated from the vacuum and $\mathrm{HCl}$ introduced at a pressure equal to the external atmospheric pressure. The virtually instantaneous color change indicated the protonation reaction to be rapid. Thorough mixing was achieved by stirring for several minutes. Then the vacuum stopcock was closed and the hydrochlorination cell disconnected from the manometric apparatus. The solution was then carefully poured into the cuvette by tipping the cell so that the solution filled all the space between the walls of the cuvette and the insert. The electronic spectrum was then recorded. In several experiments, the arene solution was first equilibrated with $\mathrm{HCl}$ at $\mathrm{ca} .1 \mathrm{~atm}$ and then, with the solution still in the side arm, the cell was evacuated (care, frothing) until gas bubbles no longer formed. Then the cell was back-filled with Ar, disconnected from the manometric apparatus, and tilted so as to fill the cuvette with solution, after which the spectrum was recorded. In experiments on the effect of $P_{\mathrm{HCl}}$ on the protonation of $\mathrm{V}$, the cell was filled with $\mathrm{HCl}$ to a predetermined pressure. After the mixture was stirred for several minutes, the $\mathrm{HCl}$ pressure was measured. Then the cell was closed and disconnected, the cuvette was filled, and the spectrum was recorded.

Acknowledgment. We are grateful to Dr. R. R. Chambers for the sample of III and to Dr. J. S. Wilkes for supplying us with a computer program from which we calculated $C_{\mathrm{Cl}}$. This research was sponsored by the Division of Chemical Sciences, Office of Basic Energy Sciences, U.S. Department of Energy, under Contract DE-AC05-840R21400 with Martin Marietta Energy Systems, Inc.

\title{
Structure and Optical Properties of CdS Superclusters in Zeolite Hosts
}

\author{
Norman Herron, ${ }^{*, \dagger}$ Ying Wang, ${ }^{\dagger}$ Mike M. Eddy, ${ }^{\ddagger}$ Galen D. Stucky, ${ }^{\ddagger}$ Dave E. Cox, ${ }^{\S}$ \\ Karin Moller," and Thomas Bein"
}

Contribution No. 4571 from the Central Research and Development Department, E. I. du Pont de Nemours and Company, Wilmington, Delaware 19898, Department of Chemistry, University of California, Santa Barbara, California 93106, Department of Physics, Brookhaven National Laboratories, Upton, Long Island, New York 11973, and Department of Chemistry, University of New Mexico, Albuquerque, New Mexico 87131. Received December 3, 1987.

Revised Manuscript Received August 16, 1988

\begin{abstract}
Direct synthesis of CdS within the pore structure of zeolites leads to a novel supercluster with a structural geometry superimposed by the host framework. Detailed X-ray powder diffraction and EXAFS analysis together with optical absorption data reveal discrete $(\mathrm{CdS}, \mathrm{O})_{4}$ cubes located within the small sodalite units of the structure which begin to interconnect as the loading density within the zeolite rises. The discrete cube building blocks consist of interlocking tetrahedra of $\mathrm{Cd}$ and $\mathrm{S}$ with a CdS bond length of $2.47 \AA$. At higher loadings these cubes begin to occupy adjacent sodalite units where the Cd atoms point toward each other through the double six-rings linking the sodalite moieties with a Cd-Cd distance of $\sim 6 \AA$. As this three-dimensional interconnection proceeds, the corresponding changes in optical properties indicate a progression toward a semiconductor supercluster with behavior intermediate between that of the discrete CdS cubes and bulk semiconductor. Semiconductor superclusters of this type represent a novel class of materials where the three-dimensional structure and electronic properties can be controlled by using different zeolites as the template. The unique stability of the semiconductor clusters inside the sodalite units is due to the coordination of $\mathrm{Cd}$ atoms with the framework oxygen atoms of the double six-ring windows. The stability of the supercluster comes from the interaction between clusters in the adjacent sodalite units. We suggest that through-bond coupling is responsible for the interaction between clusters.
\end{abstract}

\section{Introduction}

Small metal and semiconductor clusters, having hybrid molecular and bulk properties, represent a new class of materials and are under intensive investigation. Many approaches exist for preparing these small clusters. Well-defined, mass-selected clusters

\footnotetext{
${ }^{\dagger}$ E. I. du Pont de Nemours and Co.

University of California.

Brookhaven National Laboratories.

"University of New Mexico.
}

up to hundreds of atoms can be generated in the gas phase with supersonic jet expansion techniques. ${ }^{1-3}$ Many interesting properties of these "bare" clusters, including chemical reactivities, have been studied, although direct structure determination of these

(1) Kroto, H. W.; Heath, J. R.; O'Brien, S. C.; Curl, R. F.; Smalley, R. E. Nature 1985, 318, 162 .

(2) Rohlfing, E. A.; Cox, D. M.; Kaldor, A. Chem. Phys. Lett. 1983, 99, 161.

(3) Riley, S. J.; Parks, E. K.; Mao, L.; Pobo, G.; Wexler, S. J. Phys. Chem. 1982, 86, 3911 .

(C) 1989 American Chemical Society 
clusters is still not available. Clusters can also be prepared in the condensed phase where the environment necessarily plays an important role. Small semiconductor clusters and particles have been prepared in solutions, ${ }^{4-12}$ glasses, ${ }^{13,14}$ and polymers. ${ }^{15,16}$ In these systems, the sizes of the clusters are not as well-defined. However, it can be varied to cover almost the entire range from molecular to bulk. ${ }^{16}$ Another approach, perhaps the most desirable one, if it is generally feasible, is through systematic chemical synthetic techniques. The syntheses of large gold and silver clusters have been reported recently. ${ }^{17}$ To the best of our knowledge, this has not been done for semiconductor clusters.

Well-defined clusters can also be synthesized inside zeolites. Zeolites are crystalline $\mathrm{Al}-\mathrm{O}-\mathrm{Si}$ materials containing pores of molecular dimensions, interconnected by smaller windows. For example, zeolite $\mathrm{Y}$ contains both $5-\AA$ (sodalite cage) and $13-\AA$ (supercage) pores. Using zeolites as hosts, in principle, one can generate well-defined clusters inside these pores. This approach has been used for generating silver clusters inside zeolites. ${ }^{18}$ Furthermore, by filling up all the internal pores of zeolites, one can build novel three-dimensional supercluster structures that consist of individual clusters interconnected through the windows of the pores. When different zeolites are used as the template, superclusters with different structures and electronic properties can be built. In this paper we present the synthesis and structure determination of CdS superclusters inside zeolites and discuss their optical and electronic properties. Part of the results has been presented in a previous communication. ${ }^{19}$ In a separate paper, ${ }^{20}$ we discussed the properties of selenium clusters in zeolites.

\section{Experimental Section}

A. Synthesis of CdS Zeolite Composites. All three zeolite-entrapped semiconductor materials were prepared by essentially the same procedure, illustrated here for zeolite Y. Starting zeolite materials were commercially available from Linde as zeolite $5 \mathrm{~A}$, zeolite $13 \mathrm{X}$, and zeolite LZY$52(\mathrm{Na}-\mathrm{Y})$ and were used without further purification. Hydrogen sulfide gas was from Matheson while cadmium nitrate was from Alfa, and again these were used without further purification.

A total of $10 \mathrm{~g}$ of zeolite $\mathrm{Na}-\mathrm{Y}$ was slurried in $1000 \mathrm{~mL}$ of distilled water, and the $\mathrm{pH}$ was adjusted to 5 with nitric acid. A total of $10 \mathrm{~g}$ of cadmium nitrate was added and the mixture stirred at room temperature overnight. The $\mathrm{Cd}$ ion-exchanged zeolite was collected by filtration, washed extensively with distilled water, and then suction dried to a damp powder. The material was then dried and calcined in a 12 -in.-tube furnace in flowing oxygen $(100 \mathrm{~mL} / \mathrm{min})$, with the powder being a

(4) (a) Lucas, M. Bull. Soc. Chim. Fr. 1896, 15(3), 40. (b) Ewan, T. J Soc. Chem. Ind., London 1909, 10, 10.

(5) Berry, C. R. Phys. Rev. 1967, 161,848.

(6) (a) Brus, L. E. J.Phys. Chem. 1986, 90,2555 and references therein. (b) Brus, L. E. J. Chem. Phys. 1984, 80, 4403. (c) Rossetti, R.; Hull, R.; Gibson, J. M.; Brus, L. E. J. Chem. Phys. 1985, 83, 1406.

(7) Weller, H.; Schmidt, H. M.; Koch, U.; Fojtik, A.; Baral, S.; Henglein, A.; Kunath, W.; Weiss, K.; Dieman, E. Chem. Phys. Lett. 1986, 124, 557, and references therein.

(8) (a) Nozik, A. J.; Williams, F.; Nenadovic, M. T.; Rajh, T.; Micic, O. I. J. Phys. Chem. 1985, 89, 397. (b) Nedeljkovic, J. M.; Nenadovic, M. T.; Micic, O. I.; Nozik, A. J. J. Phys. Chem. 1986, 90, 12.

(9) Ramsden, J. J.; Webber, S. E.; Gratzel, M. J. Phys. Chem. 1985, 89 2740

(10) Tricot, Y.-M; Fendler, J. H. J. Phys. Chem. 1986, 90, 3369.

(11) (a) Sandroff, C. J.; Hwang, D. M.; Chung, W. M. Phys. Rev. B, 1986, 33, 5953. (b) Sandroff, C. J.; Farrow, L. A. Chem. Phys. Lett 1986, 130 458. (c) Sandroff, C. J.; Kelty, S. P.; Hwang, D. M. J. Chem. Phys. 1986, 85,5337

(12) Dannhauser, T.; O'Neil, M.; Johansson, K.; Whitten, D.; McLendon, G. J. Phys. Chem. 1986, 90,6074.

(13) (a) Ekimov, A. I.; Onushchenko, A. A. JETP Lett. (Engl. Transl.) 1984, 40,1136. (b) Ekimov, A. I.; Efros, Al. L.; Onushchenko, A. A. Solid State Commun. 1985, 56, 921. (c) Efros, Al. L.; Efros, A. L. Sov. Phys.Semicond. (Engl. Transl) 1982, 16, 772.

(14) Borrelli, N. F.; Hall, D. W.; Holland, H. J.; Smith, D. W. J. Appl Phys. 1987, 61, 5399.

(15) Wang, Y.; Mahler, W. Opt. Commun. 1987, 61, 233

(16) Wang, Y.; Suna, A.; Mahler, W.; Kasowski, R., accepted for publication in $J$. Chem. Phys.

(17) Teo, B. K.; Keating, K.; Kao, Y.-H. J. Am. Chem. Soc. 1987, 109, 3494

(18) Baker, M.; Godber, J.; Ozin, G. A. J. Phys. Chem. 1985, 89, 2299

(19) Wang, Y.; Herron, N. J. Phys. Chem. 1987, 91, 257.

(20) Parise, J. B.; MacDougall, J.; Herron, N.; Farlee, R.; Sleight, A. W.;

Wang, Y.; Bein, T.; Moller, K.; Moroney, L. M. Inorg. Chem. 1988, 27, 221.
Table I. Chemical Analysis and Nomenclature of CdS-Loaded Zeolites

\begin{tabular}{cccc}
\hline zeolites & unit cell formula calcd & wt \% CdS & UC designation \\
\hline $\mathrm{Y}^{a}$ & $\mathrm{Cd}_{1.6} \mathrm{~S}_{4.0} \mathrm{Al}_{56} \mathrm{Si}_{136}$ & 1.0 & $\mathrm{CdS}-\mathrm{Y} \mathrm{1}$ \\
$\mathrm{Y}$ & $\mathrm{Cd}_{2.3} \mathrm{~S}_{4.1} \mathrm{Al}_{56} \mathrm{Si}_{136}$ & 1.8 & $\mathrm{CdS}-\mathrm{Y} 2$ \\
$\mathrm{Y}$ & $\mathrm{Cd}_{3.1} \mathrm{~S}_{4.5} \mathrm{Al}_{56} \mathrm{Si}_{136}$ & 3.0 & $\mathrm{CdS}-\mathrm{Y} 3$ \\
$\mathrm{Y}$ & $\mathrm{Cd}_{5.5} \mathrm{~S}_{4.6} \mathrm{Al}_{56} \mathrm{Si}_{136}$ & 5.4 & $\mathrm{CdS}-\mathrm{Y} 5$ \\
$\mathrm{Y}$ & $\mathrm{Cd}_{5.8} \mathrm{~S}_{5.0} \mathrm{Al}_{56} \mathrm{Si}_{136}$ & 5.9 & $\mathrm{CdS}-\mathrm{Y} 6$ \\
$\mathrm{Y}$ & $\mathrm{Cd}_{10.4} \mathrm{~S}_{11.0} \mathrm{Al}_{56} \mathrm{Si}_{136}$ & 11.3 & $\mathrm{CdS}-\mathrm{Y} 11$ \\
$\mathrm{Y}$ & $\mathrm{Cd}_{13.4} \mathrm{~S}_{14.6} \mathrm{Al}_{56} \mathrm{Si}_{136}$ & 11.8 & $\mathrm{CdS}-\mathrm{Y} 12$ \\
$\mathrm{Y}$ & $\mathrm{Cd}_{13.5} \mathrm{~S}_{10.3} \mathrm{Al}_{56} \mathrm{Si}_{136}$ & 13.0 & $\mathrm{CdS}-\mathrm{Y} 13$ \\
$\mathrm{Y}$ & $\mathrm{Cd}_{18.6} \mathrm{~S}_{6.7} \mathrm{Al}_{56} \mathrm{Si}_{136}$ & 16.0 & $\mathrm{CdS}-\mathrm{Y} 16$ \\
$\mathrm{Y}$ & $\mathrm{Cd}_{22.6} \mathrm{~S}_{24} \mathrm{Al}_{56} \mathrm{Si}_{136}$ & 18.2 & $\mathrm{CdS}-\mathrm{Y} \mathrm{18}$ \\
$\mathrm{X}$ & $\mathrm{Cd}_{21.0} \mathrm{~S}_{14.0} \mathrm{Al}_{90} \mathrm{Si}_{102}$ & 18.8 & $\mathrm{CdS}-\mathrm{X} \mathrm{19}$ \\
$\mathrm{X}$ & $\mathrm{Cd}_{29.1} \mathrm{~S}_{30.0} \mathrm{Al}_{86} \mathrm{Si}_{106}$ & 24.8 & $\mathrm{CdS}-\mathrm{X} 25$ \\
$\mathrm{~A}$ & $\mathrm{Cd}_{2.3} \mathrm{~S}_{2.6} \mathrm{Al}_{12} \mathrm{Si}_{12}$ & 17.0 & $\mathrm{CdS}-\mathrm{A} \mathrm{17}$ \\
$\mathrm{A}$ & $\mathrm{Cd}_{4.0} \mathrm{~S}_{3.3} \mathrm{Al}_{12} \mathrm{Si}_{12}$ & 25.6 & $\mathrm{CdS}-\mathrm{A} \mathrm{26}$ \\
\hline
\end{tabular}

${ }^{a} 8$ sodalite units/unit cell. ${ }^{b} 1$ sodalite unit/unit cell.

\section{a}

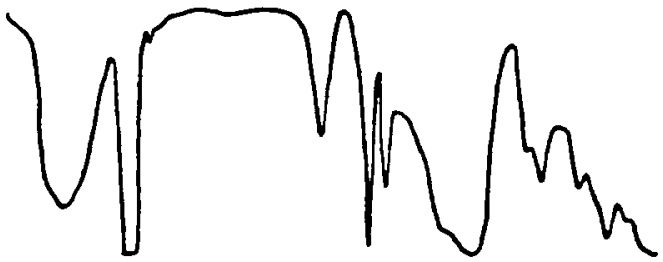

b

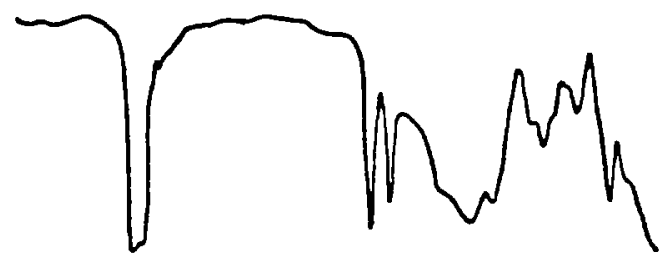

C

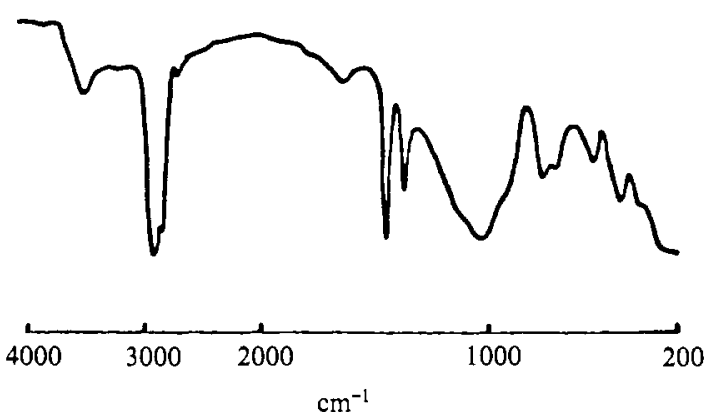

Figure 1. IR spectra (Nujol mull) of (a) zeolite $\mathrm{Na}-\mathrm{Y}$ (hydrated), (b) $\mathrm{Cd}^{2+}$ ion-exchanged $\mathrm{Y}$ (dehydrated), and (c) $\mathrm{CdS}$ in zeolite $\mathrm{Y}(\mathrm{CdS}-\mathrm{Y}$ 13).

maximum of $1 / 4$-in. deep throughout the bed. A slow-temperature ramp from room temperature to $400^{\circ} \mathrm{C}$ over $2 \mathrm{~h}$ followed by a hold at $400^{\circ} \mathrm{C}$ for a further $1 \mathrm{~h}$ gave a dry white powder. The sample was cooled in vacuo to $100^{\circ} \mathrm{C}$ over $1 \mathrm{~h}$ and then exposed to flowing hydrogen sulfide $\left(40 \mathrm{~mL} / \mathrm{min}\right.$ ) at $100^{\circ} \mathrm{C}$ for $30 \mathrm{~min}$, the effluent $\mathrm{H}_{2} \mathrm{~S}$ being passed through hypochlorite scrubbers before being vented through an efficient fume hood. Finally, the still white zeolite was evacuated at $100^{\circ} \mathrm{C}$ for 30 min under vacuum before the sample was sealed and transferred to a dry nitrogen glovebox for storage. During the final evacuation the white zeolite becomes pale yellow-cream, and this color change is reversible in that treatment with additional $\mathrm{H}_{2} \mathrm{~S}$ returns the zeolite to the original white color. ${ }^{21}$

Variations on this basic procedure were in adjusting the original $\mathrm{pH}$ of the zeolite slurry to 6.5 rather than 5 for the more acid-sensitive zeolites $\mathrm{A}$ and $\mathrm{X}$. Different $\mathrm{Cd}$ loadings were achieved by controlling

(21) Wang, Y.; Herron, N. J. Phys. Chem. 1987, 91, 5005. 
Table II. IR Absorption Bands $\left(\mathrm{cm}^{-1}\right)$ of Zeolite $\mathrm{Y}$ during CdS Synthesis (Nujol Mull)

\begin{tabular}{lllccc}
\hline & asym stretch & sym stretch & $\begin{array}{c}\text { double } \\
\text { rings }\end{array}$ & T-O bend & pore opening \\
\hline Na-Y (starting material) & 1130,1005 & $784,714,635$ & 572 & 500,455 & 380,260 \\
Cd-Y (calcined) & $1145,1040,945$ & $780,710,635$ & 580 & 450 & 380 \\
CdS-Y 13 & $1135,1050,955$ & 780,715 & 555 & 490,440 & 375 \\
\hline
\end{tabular}

the amount of $\mathrm{Cd}$ in the ion-exchange solutions.

All samples were water-sensitive (including atmospheric moisture) to a varying extent. Zeolites $\mathrm{X}$ and $\mathrm{Y}$ immediately become deep yelloworange upon immersion in water or any polar, nonbasic solvent. Zeolite A slowly evolved a yellow-orange color over a longer $(\sim 1 \mathrm{~h})$ period when immersed in water. To avoid this semiconductor migration and aggregation, the samples must be stored and handled in a rigorously dry atmosphere.

B. Characterization of CdS Zeolite Composites. Chemical analyses of zeolite composites were performed by Galbraith Laboratories, Knoxville, TN, with atomic absorption. Chemical analyses and nomenclature of samples used in this study are listed in Table I. X-ray photoelectron spectroscopy of the samples as prepared was unable to detect any $\mathrm{Cd}$ in the outer $50 \AA$ of the zeolite particles even in the very highest loaded samples. This confirms that essentially all of the CdS is within the zeolite pore structure in the absence of solvent-induced migration. ESR spectra of the samples showed no signal other than that expected for $\mathrm{Fe}$ and $\mathrm{Mn}$ impurities in the zeolite host. IR spectra of these materials were unable to detect any SH groups after the final evacuation but showed the expected $\mathrm{OH}$ groups. Significant shifts in the framework tetrahedral atoms (i.e. $\mathrm{Si}$ or $\mathrm{Al}$ ) oxygen bonds ( $\mathrm{T}-\mathrm{O}$ bonds), as shown in Figure 1 and listed in Table II, indicate a strong interaction between the encapsulated CdS clusters and the zeolite framework, which is confirmed by the X-ray results listed below.

C. Diffuse Reflectance Measurements. The absolute absorption coefficients of these semiconductor clusters were obtained by the diffuse reflectance theory of Kubelka-Munk (K-M) ${ }^{22}$ (eq 1) where $\alpha$ is the

$$
\alpha=S F(R) / 2 \nu_{\mathrm{p}}
$$

absorption coefficient (in units of $1 / \mathrm{cm}$, normalized to the volume fraction of the semiconductor), $S$ is the scattering coefficient, $\nu_{\mathrm{p}}$ is the volume fraction of the semiconductor, and $F(R)$ is the $\mathrm{K}-\mathrm{M}$ function defined as in eq 2 where $R$ is the experimentally measured diffuse re-

$$
F(R)=1-R^{2} / 2 R
$$

flectance. The K-M function of the semiconductor, corrected for the zeolite absorption, is given in eq 3 where $\nu_{\mathrm{d}}$ is the volume fraction of the

$$
F\left(R_{\mathrm{s}}\right)=F\left(R_{\text {composite }}\right)-\left(\nu_{\mathrm{d}}-\nu_{\mathrm{p}} / \nu_{\mathrm{d}}\right) F\left(R_{\text {reolite }}\right)
$$

diluent. The reflectance of the CdS zeolite sample is measured directly if the CdS loading is low. For high-loading samples, it is necessary to dilute with either pure zeolite or $\mathrm{BaSO}_{4}$ due to the strong absorption.

We have used either a Cary 14 or an IBM UV-vis spectrometer, both equipped with a dual-channel diffuse reflectance attachment. The different responses from the two channels are corrected by taking the ratio of the diffuse reflectances of $\mathrm{BaSO}_{4}$ at both the sample and reference ports. The relative reflectances of pure zeolites and CdS zeolite composites are then measured against the $\mathrm{BaSO}_{4}$ reference. The $\mathrm{K}-\mathrm{M}$ function of the semiconductor, $F\left(R_{s}\right)$, is then calculated with eq 2 and 3 , by using the literature value for the absolute reflectance of $\mathrm{BaSO}_{4} \cdot{ }^{23}$

To obtain the absolute absorption coefficient, one has to know the scattering coefficient of the sample. When $\mathrm{BaSO}_{4}$ is used as diluent, the literature value of the scattering coefficient of $\mathrm{BaSO}_{4}$ is used. ${ }^{24}$ When the diluent is zeolite, its scattering coefficient has to be independently measured by using $\mathrm{g}^{22,24}$ eq 4 where $R_{\alpha}, R$, and $R_{\mathrm{g}}$ represent diffuse re-

$$
S=(1 / d)\left[R_{\alpha} /\left(1-R_{\alpha}\right)^{2}\right] \ln \frac{\left(R_{\alpha} R-1\right)\left(R_{\mathrm{g}}-R_{\alpha}\right)}{\left(R_{\alpha} R_{\mathrm{g}}-1\right)\left(R-R_{\alpha}\right)}
$$

flectances from a thick sample, a thin sample with thickness $d$, and the dark background, respectively. Details of this method can be found elsewhere in ref 22 . The wavelength dependence of the scattering coefficient of zeolite is gradual in the wavelength region of interest, and

(22) Reflectance Spectroscopy; Kortum, G. Ed.; Springer-Verlag: New York, 1969 .

(23) Grum, F.; Wightman, T. E. Appl. Opt. 1977, 16, 2775

(24) Patterson, E. M.; Shelden, C. E.; Stockton, B. H. Appl. Opt. 1977 , 16,729 . therefore the $\mathrm{K}-\mathrm{M}$ function is a good representation of the absorption spectrum. In this work, we have determined the absolute absorption coefficients for certain selected samples only. The K-M function, which has the same shape as the absorption spectrum, is reported for the rest of the samples.

D. Powder Synchrotron X-ray Diffraction. High-resolution X-ray powder diffraction data were collected for two different samples of CdS in zeolite $\mathrm{Y}$ on the powder diffractometer at beam line $\mathrm{X} 13 \mathrm{~A}$ at the Brookhaven National Synchrotron Light source. The samples contained $13.5 \mathrm{Cd}$ with $10.3 \mathrm{~S}$ (CdS-Y 13) and $18.6 \mathrm{Cd}$ with $6.7 \mathrm{~S}(\mathrm{CdS}-\mathrm{Y} \mathrm{16)}$ per unit cell ( $8: 8$ supercages/sodalite units). A perfect $\mathrm{Ge}(111)$ crystal scattering in the horizontal plane was used as a monochromator of the incident X-rays. The sample and $\operatorname{LiF}(400)$ analyzer crystal scatter vertically. For a full description of the diffractometer geometry at X13A, see ref. 25. The samples were packed into flat aluminum holders and the contents protected from moisture by sealing with thin beryllium foil. The data were collected by step-scanning from $5^{\circ}$ to a maximum of $98^{\circ}$ in intervals of $0.01^{\circ}$ for periods of 2-10 s. Longer counting times are required at higher scattering angles to counteract the falloff in the form factor. The wavelength was determined to be $1.5466 \AA$ by calibration with a Si standard. The sample container was rocked $2^{\circ}$ at each data point to reduce the effects of preferred orientation. An ion chamber filled with nitrogen was placed before the sample in order to monitor the incident beam intensity. Beam size was $2.5 \times 1 \mathrm{~mm}$ in the horizontal and vertical directions, respectively, and the intensity at the sample position was $\sim 10 \mathrm{e}^{10}$ photons/s for a storage ring current of $100 \mathrm{~mA}$.

The Be foil protected the samples from moisture successfully as judged by the sample coloration after data collection. Since Be is highly crystalline, the foil showed only a small number of sharp reflections, which could be easily excluded from the refinement with a minimum loss of zeolite data.

The structural refinements were carried out by standard profile refinement techniques. The initial normalizations of the data were performed with programs available at Brookhaven while for structural refinement a modification of the original Rietveld program was employed. This program incorporates the Voigt peak-shape description that is essential for analysis of powder patterns collected with the two-crystal configuration employed at X13A. The extra-framework material was revealed by standard Fourier methods.

E. Extended X-ray Absorption Fine-Structure Studies. EXAFS experiments were carried out at the X-11A beam line at the Brookhaven National Synchrotron Lightsource with a stored electron energy of $2.5 \mathrm{G}$ $\mathrm{eV}$ and ring currents between 40 and $130 \mathrm{~mA}$. Transmission Cd K-edge $(26711 \mathrm{eV})$ data were collected with a $\mathrm{Si}(400)$ crystal monochromator and ionization chambers filled with $\operatorname{Ar}\left(\mathrm{l}_{0}\right)$ and $\operatorname{Kr}(1)$.

The zeolite samples were embedded in a 1:1 dodecane/octadecane mixture under inert atmosphere in a Vacuum Atmosphere drybox. They were kept under nitrogen until the EXAFS measurements were carried out. Data collection was done at liquid-nitrogen temperature, scanning up to $1500 \mathrm{eV}$ above the absorption edge. At least two scans per sample (20 min) were taken.

The sample thickness was calculated to give an absorption step $\mu x$ between 0.7 and 1 and a total absorption of less than 2 . The data were analyzed with the University of Washington EXAFS program following published procedures. ${ }^{26}$ Background removal was accomplished with a cubic spline function. The resulting EXAFS modulations were weighted by $k^{3}$ ( $k$, electron wave vector) and Fourier transformed (FT) over a range $k=2-15\left(\AA^{-1}\right)$. Data of reference and unknown were consistently treated as similarly as possible to avoid artifacts.

EXAFS measurements were performed on the following samples: $\mathrm{Cd}-\mathrm{Y}\left(\mathrm{Cd}_{18.3} \mathrm{Na}_{19.4} \mathrm{Al}_{56} \mathrm{Si}_{136}\right)$, simple $\mathrm{Cd}$ exchanged zeolite $\mathrm{Y}, \mathrm{CdS}-\mathrm{Y}$ 6 , and $\mathrm{CdS}-\mathrm{Y} 16$. References used were $\mathrm{CdS}, \mathrm{Cd}\left(\mathrm{NO}_{3}\right)_{2} \cdot 4 \mathrm{H}_{2} \mathrm{O}$, and PdO. EXAFS reference parameters were extracted as follows:

$\mathrm{PdO}$ was used (a) as a reference for the $\mathrm{Cd}$-oxygen coordination sphere by applying an inverse Fourier transformation (IFT) to the first shell (reference values $R=2.01 \AA$ and $N=4^{27}$ ) and (b) as reference for

(25) Cox, D. E.; Hastings, J. B.; Cardoso, L. P.; Finger, L. W. Mat. Sci. Forum 1986, 9 , 1

(26) Lee, P. A.; Citrin, P. H.; Eisenberger, P.; Kincaid, B. M. Rev. Mod. Phys. 1981, 53, 769. 
Table III

\begin{tabular}{|c|c|c|c|c|}
\hline \multirow[b]{2}{*}{ scatterer pair } & \multirow{2}{*}{$\begin{array}{l}\text { bond distance } \\
(R), \AA\end{array}$} & \multicolumn{2}{|c|}{ coord no. } & \multirow{2}{*}{$\begin{array}{c}\text { Debye-Waller } \\
\Delta G^{2}, \AA^{2}\end{array}$} \\
\hline & & $N$ & $N_{\text {corr }}{ }^{a}$ & \\
\hline \multicolumn{5}{|c|}{$\mathrm{Cd}-\mathrm{Y}$} \\
\hline $\mathrm{Cd}-\mathrm{OZ}$ & 2.44 & 2.6 & 3.0 & 0.004 \\
\hline $\mathrm{Cd}-\mathrm{O} /$ cube & 2.25 & 2.2 & 2.4 & 0.0007 \\
\hline $\mathrm{Cd}-\mathrm{O} /$ supercage & 2.34 & 2.3 & 2.5 & 0.002 \\
\hline $\mathrm{Cd}-\mathrm{Si} / \mathrm{Al}$ & 3.42 & 9.3 & 12.4 & -0.0014 \\
\hline $\mathrm{Cd}-\mathrm{Cd} /$ cube & 3.29 & 2.1 & 2.0 & 0.003 \\
\hline \multicolumn{5}{|c|}{ CdS-Y 6} \\
\hline $\mathrm{Cd}-\mathrm{OZ} /$ fragment & 2.36 & 3.1 & 3.5 & 0.004 \\
\hline $\mathrm{Cd}-\mathrm{O} /$ cube & 2.24 & 1.7 & 1.8 & 0.0007 \\
\hline $\mathrm{Cd}-\mathrm{S} /$ fragment & 2.52 & 1.5 & & 0.0009 \\
\hline $\mathrm{Cd}-\mathrm{Si} / \mathrm{Al}$ & 3.42 & 9.3 & 12.4 & -0.0014 \\
\hline $\mathrm{Cd}-\mathrm{Cd} /$ cube & 3.29 & 2.1 & 2.0 & 0.003 \\
\hline \multicolumn{5}{|c|}{ CdS-Y 16} \\
\hline $\mathrm{Cd}-\mathrm{OZ} /$ fragment & 2.44 & 2.0 & 2.3 & 0.004 \\
\hline $\mathrm{Cd}-\mathrm{O} /$ cube & 2.23 & 2.2 & 2.4 & 0.0009 \\
\hline $\mathrm{Cd}-\mathrm{O} /$ supercage & 2.32 & 1.7 & 1.9 & 0.004 \\
\hline $\mathrm{Cd}-\mathrm{S} /$ fragment & 2.52 & 1.0 & & 0.001 \\
\hline $\mathrm{Cd}-\mathrm{Si} / \mathrm{Al} / \mathrm{Cd}$ & 3.40 & 6.7 & 8.9 & 0.0009 \\
\hline
\end{tabular}

${ }^{a}$ Coordination numbers corrected for the mean free path difference in reference and unknown.

the Cd-Cd contribution in the CdO cluster (IFT on the third shell; reference values $R=3.42$ and $N=8$ ). In case (a) the back-scattering atoms are identical between model and sample compound but differ in the absorber atoms. Phase transferability for $\mathrm{Cd}$ to its second nearest neighbor can be assumed. ${ }^{28}$ The use of the Pd-Pd scatter pair as a model for a $\mathrm{Cd}-\mathrm{Cd}$ contribution in the unknown assumes, in addition, the transferability for back-scattering amplitude function. Amplitude transferability, in principle, is more limited than phase transferability but is less sensitive toward changes in higher $\mathrm{Z}$ elements. $\mathrm{Pd}$ and $\mathrm{Cd}$ possess a similar amplitude function, and as shown by Lengeler ${ }^{28}$ a deviation of around $0.02 \AA$ from the real bond distance has to be anticipated. Errors in the coordination number may be $\pm 30 \%$. Occurrence of four, large deviating bond distances of cadmium nitrate $\left(2.26-2.59^{29}\right)$ made this sample only useful as a qualitative reference for the $\mathrm{Cd}-\mathrm{O}$ scatter pair.

CdS supplied reference data for (a) the sulfur scatterer (reference values $R=2.52 \AA$ and $N=4^{30}$ ) and (b) for the $\mathrm{Si} / \mathrm{Al}$ neighbor contribution from the zeolite framework. The same argument as above holds for using $\mathrm{CdS}$ as reference for $\mathrm{Cd}-\mathrm{Si} / \mathrm{Al}$. Distinction between $\mathrm{Si}$ and $S$ in the unknown sample by using the same reference is easily obtained, because their possible bond distances are about $1 \AA$ different (Cd-S, 2.5 $\AA ; \mathrm{Cd}-\mathrm{O}-\mathrm{Si}, 3.2-3.5 \AA$ ). Application of $\mathrm{CdS}$ for a second-shell $\mathrm{Si}$ reference is assumed to introduce only minor errors, since bond angles between $\mathrm{Cd}-\mathrm{O}-\mathrm{Si}$ are $<150^{\circ}$ and will therefore not contribute to multiple scattering. A mean free path correction was applied in all instances where the bond distance of the reference and the actual value differ by more than $0.1 \AA$ (see Table III).

\section{Results}

A. Optical Properties of CdS Clusters in Zeolite Y. The optical absorption spectra of CdS in zeolite $\mathrm{Y}$ are shown in Figure 2 and have been discussed previously. ${ }^{19}$

The unique concentration dependence of the absorption spectra suggests a percolative phenomenon. ${ }^{31}$ At low concentrations, $\mathrm{CdS}$ exists as isolated molecules or small clusters within the zeolite pores. At high concentrations, they must aggregate together, through the windows of the pores, to form a supercluster by a percolative process. The observed percolation threshold is around $4 \pm 1 \mathrm{wt} \%$. In the next section we will present results from X-ray diffraction and EXAFS studies and will show that these conclusions are supported by the structural data and are consistent with the percolation theory. The steady evolution of an exciton-like feature at $350 \mathrm{~nm}$ as the CdS loading density increases indicates

(27) Wasser, J.; Levy, H. A.; Peterson, S. W. Acta Crystallogr. 1953, 6,

(28) Eisenberger, P.; Lengeler, B. Phys. Rev. B. 1980, 22, 3551. Lengeler, B. J. Phys. Collog. 1986, 8, 75 .

(29) Matkovic, B.; Ribar, B.; Zelenko, B.; Peterson, S. Acta Crystallogr. 1966, 21,719

(30) Wyckhoff, R. W. G. Crystal Structures, 2nd ed,; Interscience: New York, 1963 .

(31) Kirkpatrick, S. Rev. Mod. Phys. 1973, 45, 574, and references therein.

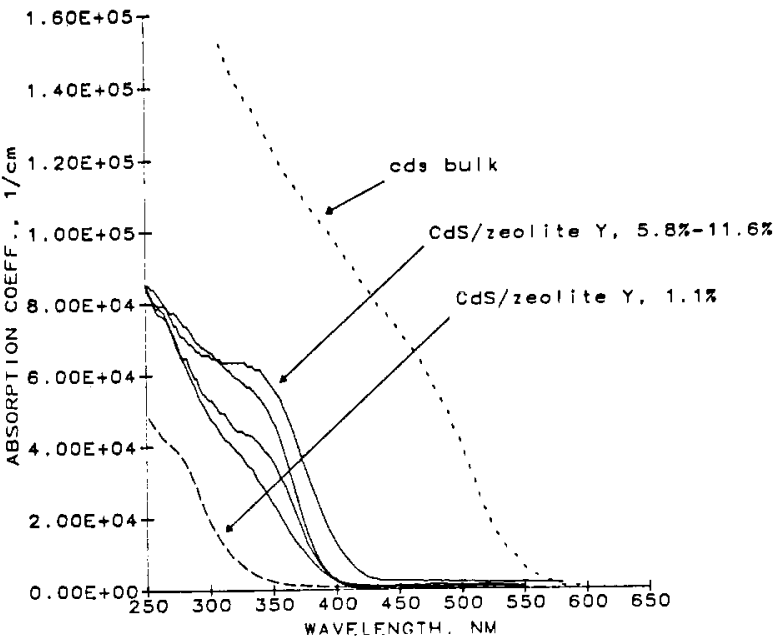

Figure 2. Absorption spectra of bulk CdS and CdS clusters in zeolite $\mathrm{Y}$ : dotted line, bulk CdS; dashed line, CdS-Y 1; solid lines, CdS-Y 5, $\mathrm{CdS}-\mathrm{Y} 6, \mathrm{CdS}-\mathrm{Y} 11, \mathrm{CdS}-\mathrm{Y} 13$. (Spectral intensity at $350 \mathrm{~nm}$ increases as loading density increases.)
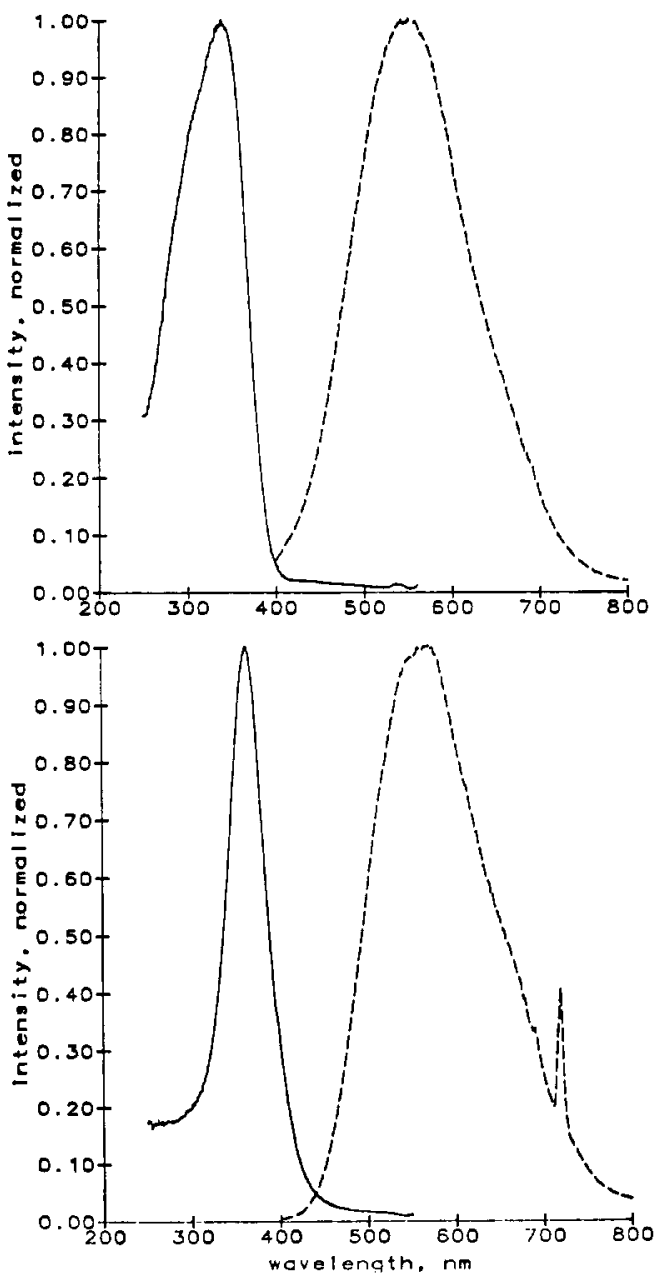

Figure 3. Excitation (solid line) and emission spectra (dashed line) of $\mathrm{CdS}$ in zeolites $\mathrm{Y}$ and $\mathrm{X}$.

improved superlattice quality as the pores become more saturated with the $\mathrm{CdS}$ clusters.

The concentration dependence of the emission spectra parallels that of the absorption spectra. At low CdS concentrations, no emission can be seen down to $4 \mathrm{~K}$ (except weak zeolite emission). Once above the threshold concentration of $4 \pm 1 \mathrm{wt} \%$, emissions due to defects of $\mathrm{CdS}$ can be observed (Figure 3). The excitation spectrum shows a pronounced peak at $350-360 \mathrm{~nm}$, consistent with the shoulder of the absorption spectrum of $\mathrm{CdS}$ zeolite. 
Table IV. Refined Atomic and Structural Parameters for CdS-Y 13 and $\mathrm{CdS}-\mathrm{Y} 16^{a}$

\begin{tabular}{|c|c|c|}
\hline & CdS-Y 13 & CdS-Y 16 \\
\hline \multicolumn{3}{|l|}{$T(1)$} \\
\hline$x$ & $-0.0536(1)$ & $-0.0534(1)$ \\
\hline$y$ & 0.1251 (1) & $0.1250(1)$ \\
\hline$z$ & 0.0359 (1) & $0.0356(1)$ \\
\hline$B, \AA^{2}$ & $0.376(1)$ & $0.72(4)$ \\
\hline \multicolumn{3}{|l|}{$\mathrm{O}(1)$} \\
\hline $\begin{array}{l}\quad y=-z \\
B, \AA^{2} \\
O(2)\end{array}$ & $\begin{array}{c}-0.1063(2) \\
1.697(2)\end{array}$ & $\begin{array}{c}-0.1039(2) \\
2.5(2)\end{array}$ \\
\hline$x=y$ & $-0.0016(2)$ & $-0.0021(3)$ \\
\hline$z$ & $0.142(3)$ & $0.1429(3)$ \\
\hline$B, \AA^{2}$ & $0.465(2)$ & $1.9(2)$ \\
\hline \multicolumn{3}{|l|}{$O(3)$} \\
\hline$x=y$ & $0.0748(2)$ & $0.0753(2)$ \\
\hline$z$ & $-0.0314(4)$ & $-0.0305(3)$ \\
\hline$B, \AA^{2}$ & $0.667(3)$ & $1.0(2)$ \\
\hline \multicolumn{3}{|l|}{$\mathrm{O}(4)$} \\
\hline$x=y$ & $0.0725(2)$ & $0.0737(2)$ \\
\hline$z$ & $0.3215(3)$ & $0.3223(3)$ \\
\hline$B, \AA^{2}$ & $1.224(2)$ & $1.0(2)$ \\
\hline \multicolumn{3}{|l|}{$\mathrm{Na}(1)$} \\
\hline$x=y=z$ & 0.0 & 0.0 \\
\hline occ & $1.8(2)$ & $3.3(2)$ \\
\hline \multicolumn{3}{|l|}{$\mathrm{Na}(2)$} \\
\hline$x=y=z$ & $0.040(3)$ & \\
\hline occ & $2.9(4)$ & \\
\hline \multicolumn{3}{|l|}{$\mathrm{Na}(3)$} \\
\hline$x=y=z$ & $0.2391(4)$ & $0.2453(6)$ \\
\hline occ & $13.4(4)$ & $9.2(2)$ \\
\hline \multicolumn{3}{|l|}{$\mathrm{Cd}(4)$} \\
\hline$x$ & $0.4222(7)$ & $0.4220(6)$ \\
\hline$y$ & $0.2220(7)$ & $0.2116(6)$ \\
\hline$z$ & $0.1819(7)$ & $0.1808(7)$ \\
\hline occ & $4.1(2)$ & $8.3(2)$ \\
\hline \multicolumn{3}{|l|}{$\operatorname{Cd}(1)$} \\
\hline$x=y=z$ & $0.0686(2)$ & $0.0702(1)$ \\
\hline $\begin{array}{l}S(1) \\
x=y=z\end{array}$ & \multicolumn{2}{|c|}{$S(1)$} \\
\hline \multicolumn{3}{|l|}{$O(5)$} \\
\hline$x=y=z$ & $0.139(3)$ & $0.136(2)$ \\
\hline occ & $3.8(4)$ & $1.5(2)$ \\
\hline \multicolumn{3}{|l|}{$O(6)$} \\
\hline$x$ & $0.133(3)$ & $0.105(4)$ \\
\hline$y$ & $0.481(2)$ & $0.455(2)$ \\
\hline$z$ & $0.091(3)$ & $0.109(3)$ \\
\hline occ & $15.2(9)$ & $13.2(8)$ \\
\hline \multicolumn{3}{|l|}{$O(7)$} \\
\hline$x$ & $0.097(2)$ & $0.091(1)$ \\
\hline$y$ & $0.024(2)$ & $0.003(2)$ \\
\hline$z$ & $0.482(2)$ & $0.467(2)$ \\
\hline occ & $17.5(13)$ & $22.4(12)$ \\
\hline$a=b=c, \AA$ & $24.6627(4)$ & $24.6080(2)$ \\
\hline zero point & $2.10(4)$ & $1.94(3)$ \\
\hline$U$ & $1223(60)$ & $352(20)$ \\
\hline$V$ & $-449(32)$ & $-247(18)$ \\
\hline$W$ & $92(5)$ & $70(4)$ \\
\hline$X$ & $5.9(9)$ & $1.2(5)$ \\
\hline$Y$ & $4.1(2)$ & $4.6(2)$ \\
\hline$R_{n} \%$ & 9.3 & 10.5 \\
\hline$R_{\mathrm{pr}} \%$ & 21.2 & 21.3 \\
\hline$R_{\mathrm{wpr}}, \%$ & 21.6 & 22.0 \\
\hline$R_{e}, \%$ & 18.4 & 16.3 \\
\hline$X^{2}$ & 1.4 & 1.8 \\
\hline
\end{tabular}

\footnotetext{
${ }^{a}$ Space group $F d 3 m$ (International Tables I No. 227); origin at
} center.

Details of the photophysical study will be published in a separate paper.

B. Structure of CdS Clusters in Zeolite Y. The observed, calculated, and difference profiles for the two zeolite $Y$ samples of different CdS loading, CdS-Y 13 and CdS-Y 16, are illustrated in Figure 4. The refined atomic and profile parameters are given in Table IV with selected bond lengths and angles in Table V.
Table V. Selected Bonds Distances $(\AA)$ and Angles (deg)

\begin{tabular}{lcc}
\hline & $\mathrm{CdS}-\mathrm{Y} 13$ & $\mathrm{CdS}-\mathrm{Y} \mathrm{16}$ \\
\hline $\mathrm{T}(1)-\mathrm{O}(1)$ & 1.64 & 1.61 \\
$\mathrm{~T}(1)-\mathrm{O}(2)$ & 1.64 & 1.63 \\
$\mathrm{~T}(1)-\mathrm{O}(3)$ & 1.66 & 1.66 \\
$\mathrm{~T}(1)-\mathrm{O}(4)$ & 1.64 & 1.64 \\
mean & 1.643 & 1.635 \\
expected & 1.639 & 1.639 \\
$\mathrm{O}(1)-\mathrm{T}(1)-\mathrm{O}(2)$ & 113 & 112 \\
$\mathrm{O}(1)-\mathrm{T}(1)-\mathrm{O}(3)$ & 111 & 110 \\
$\mathrm{O}(1)-\mathrm{T}(1)-\mathrm{O}(4)$ & 108 & 110 \\
$\mathrm{O}(2)-\mathrm{T}(1)-\mathrm{O}(3)$ & 105 & 106 \\
$\mathrm{O}(2)-\mathrm{T}(1)-\mathrm{O}(4)$ & 109 & 110 \\
$\mathrm{O}(3)-\mathrm{T}(1)-\mathrm{O}(4)$ & 111 & 109 \\
$\mathrm{~T}(1)-\mathrm{O}(1)-\mathrm{T}(1)$ & 138 & 143 \\
$\mathrm{~T}(1)-\mathrm{O}(2)-\mathrm{T}(1)$ & 145 & 144 \\
$\mathrm{~T}(1)-\mathrm{O}(3)-\mathrm{T}(1)$ & 139 & 138 \\
$\mathrm{~T}(1)-\mathrm{O}(4)-\mathrm{T}(1)$ & 143 & 143 \\
$\mathrm{Na}(2)-3 \mathrm{O}(3)$ & 2.14 & \\
$\mathrm{Na}(3)-3 \mathrm{O}(2)$ & 2.43 & \\
$\mathrm{Cd}(1)-3 \mathrm{O}(3)$ & 2.48 & 2.48 \\
$\mathrm{Cd}(1)-\mathrm{O}(5)$ & 2.28 & 2.22 \\
$\mathrm{Cd}(1)-\mathrm{S}(1)$ & 2.45 & 2.45 \\
$\mathrm{Cd}(2)-\mathrm{O}(7)$ & 2.33 & 2.36 \\
$\mathrm{O}(6)-\mathrm{O}(7)$ & & 2.65 \\
\hline
\end{tabular}

Excellent refinements were obtained for both the zeolite samples and are reflected in the small values of $\chi^{2}$.

The refined structures for both samples show a zeolite framework that is very similar to that of the parent sodium zeolite. The average $\mathrm{T}-\mathrm{O}$ bond length (Table IV) is in excellent agreement with that expected for a zeolite of this $\mathrm{Si} / \mathrm{Al}$ ratio (2.61). Space group $F d 3 m$ (origin at center) was used throughout the refinements, which assumes a random arrangement of silicon and aluminum in the tetrahedral atom positions, and a suitable scattering length was calculated on the basis of the analyzed $\mathrm{Si} / \mathrm{Al}$ ratio. This proved adequate for refinement purposes. The powder peak shapes could be accurately described by the convolution of Gaussian and Lorentz functions-the Voigt function. No asymmetry could be detected in the low-angle reflections, indicating that the analyzing crystals work well at removing sample displacement effects. The variations in the refined values of $U, V$, W (the Gaussian component) from sample to sample arise from the differing amounts of disorder present in the zeolite $Y$ cages.

While the overall framework structure is as expected, there are small variations in the individual $\mathrm{T}-\mathrm{O}$ bond lengths. These are rationalized in terms of approach of both sodium and cadmium cations, and both samples show these variations. The lower loading sample (CdS-Y 13) has most of the sodium cations located at the SII site illustrated in Figure 5a. SII is within the 13- $\AA$ supercage of $\mathrm{Y}$ and results in trigonal coordination for the $\mathrm{Na}$. This location has been shown to be the most energetically favorable site for sodium. ${ }^{32}$ The $\mathrm{Cd}^{2+}$ ion is located primarily at the $\mathbf{S I}^{\prime}$ site illustrated in Figure $5 \mathrm{~b}$. This site, inside the sodalite units of the framework, is preferred by multivalent cations because some of the high charge density can be compensated by hydroxyl anions at the SII' site also in the sodalite cage (Figure 5c). The $\mathrm{Cd}$ at $\mathrm{SI}^{\prime}$ has an octahedral coordination geometry resulting from trigonal coordination to framework oxygens of the sodalite sixoxygen ring (which is part of the double six-ring interconnects of the Y structure): $\mathrm{Cd}-\mathrm{O} 2.48 \AA$; and the three $\mathrm{SII}^{\prime}$ atoms, $\mathrm{Cd}-\mathrm{S}$ $2.45 \AA$ or $\mathrm{Cd}-\mathrm{O} 2.28 \AA$. The two alternative $\mathrm{SII}^{\prime}$ sites were detected in difference Fourier syntheses and refined separately as $S$ or $O$ (from water or hydroxyl). The overall structure of the sodalite cage entrapped species is therefore a distorted cube of $(\mathrm{CdS}, \mathrm{O})_{4}$ as depicted in Figure 6. Remaining electron density assigned to $\mathrm{Cd}$ is located in the 12-ring window site III (Figure 5d) and is bound to two framework oxygens at 2.57 and $2.72 \AA$

(32) Saunders, M. J.; Catlow, C. R. A. International Conference on Zeolites, Reno, $N V, 1984$ 
a
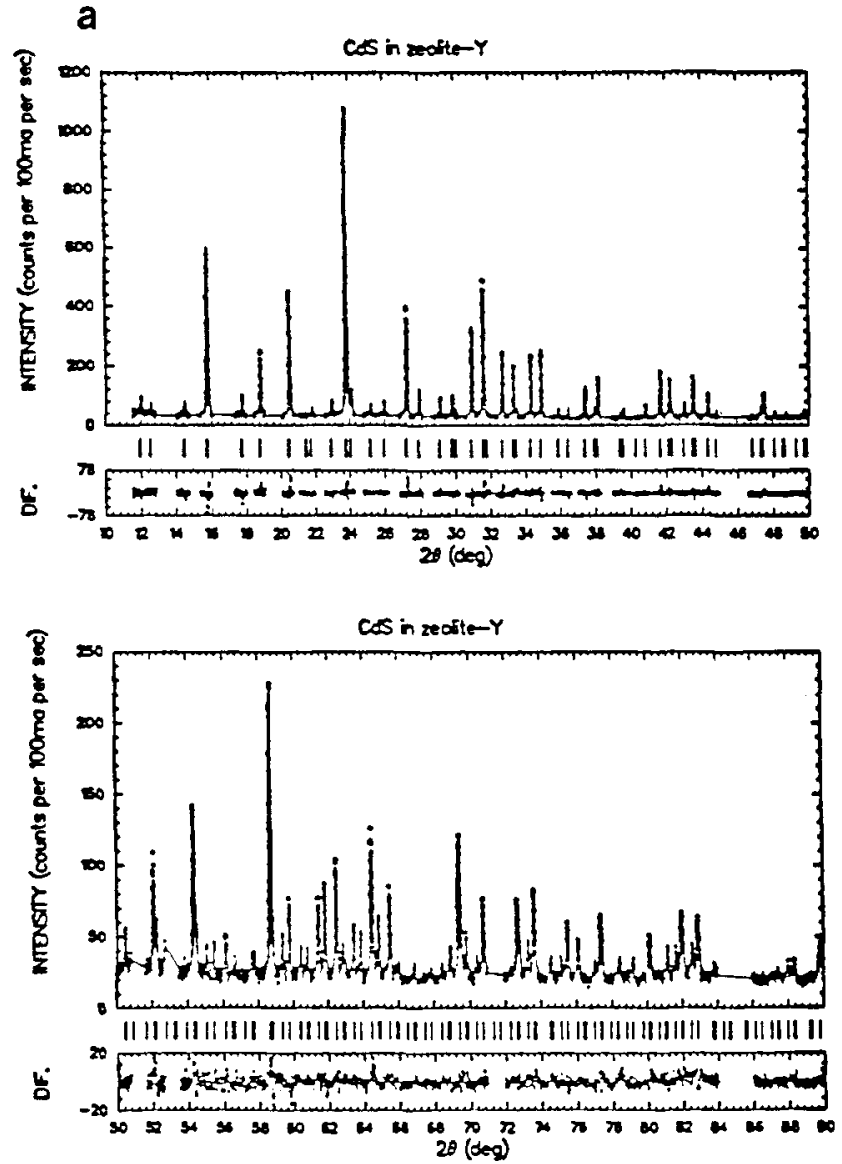
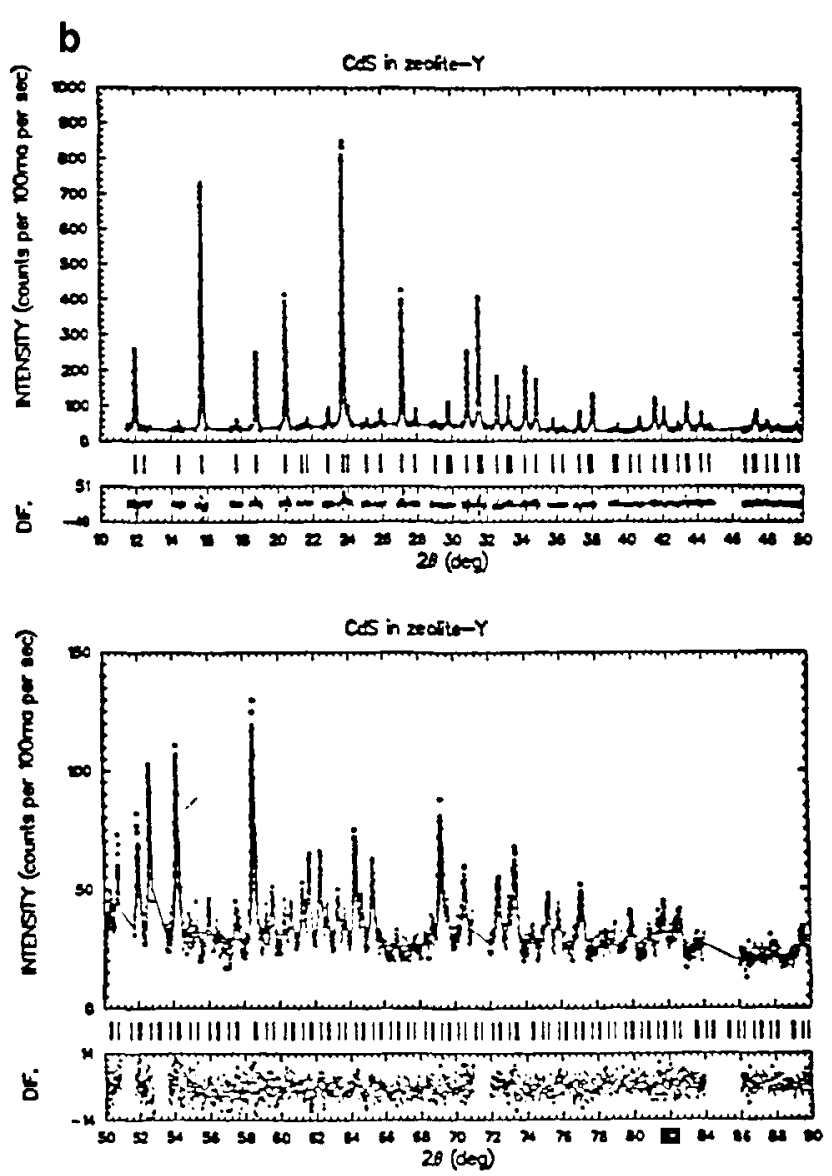

Figure 4. Observed (dots) and calculated (solid line) X-ray powder diffractogram profiles and the difference between them for (a) CdS-Y 16; (b) CdS-Y 13.

and two water molecules at 2.66 and $2.50 \AA$. The total $\mathrm{Cd}$ content based on occupancy of these two positions is 11.8 in reasonably good agreement with that found in chemical analysis (13.5).

In the higher Cd loading sample (CdS-Y 16) the same structure is observed, but now the occupancy of the SI' site has increased so that $37 \%$ of these sites are now filled compared to $24 \%$ in CdS-Y 13. Bond lengths within the cube and to the framework oxygen atoms have changed only slightly and are listed in Table $\mathrm{V}$.

In both cases we find no evidence for sulfur outside the sodalite cages so that all $\mathrm{CdS}$ species must reside there. The high occupancy of the sulfur sites within the sodalite cages is a little puzzling since the chemical analyses have shown considerably lower $S$ contents. This may be explained by either a mixed occupancy of the SII' site by both sulfur and oxygen (from water or hydroxyl), boosting the apparent occupancy by S, or else a problem with the chemical analyses of $\mathrm{S}$ in these materials. The latter is a distinct possibility in view of the equilibrium between $\mathrm{CdS}$ and $\mathrm{H}_{2} \mathrm{~S}$ discussed in section IV.F below. It is conceivable that the freshly prepared samples used in the $X$-ray work were slowly evolving $\mathrm{H}_{2} \mathrm{~S}$ continuously prior to their chemical analysis resulting in the $\mathrm{S}$ content discrepancies.

C. EXAFS Analysis. The experimentally observed EXAFS modulations contain information about the local environment of the intrazeolite $\mathrm{Cd}$ (II) ions, which is complementary to our X-ray powder diffraction results above. Each spectrum is a superposition of contributions of different coordination shells around the $\mathrm{Cd}$ absorber atom. After subtraction of the background, normali. zation, and Fourier transformation, a separation of different shells on the radial coordinate ( $R$ space) is obtained. All peaks are shifted to lower $R$ values due to phase shift effects. Figure 7 shows FT's of samples Cd-Y, CdS-Y 6, CdS-Y 16.

We discuss first the data analysis of the Cd-exchanged and oxygen-treated sample $\mathrm{Cd}-\mathrm{Y}$, which is a precursor for the $\mathrm{H}_{2} \mathrm{~S}$ treated zeolites. In a first approach to obtain information about coordination distances $(R)$ and numbers $(N)$, each of the two broad peaks in the FT was back-transformed and fitted separately with appropriate references. An attempt to fit the first peak (IFT, $1.3-2.3 \AA$ ) with only one oxygen distance failed. Best fitting results were obtained with three different $\mathrm{Cd}-\mathrm{O}$ bond lengths, the results of which are shown in Figure 8A. A qualitative comparison of the original first-shell $\mathrm{CHI}$ function with that of cadmium nitrate supports the presence of several $\mathrm{Cd}-\mathrm{O}$ distances: The $\mathrm{Cd}-\mathrm{O}_{8}$ sphere in $\mathrm{Cd}\left(\mathrm{NO}_{3}\right)_{2} \cdot 4 \mathrm{H}_{2} \mathrm{O}$ is composed of four $\mathrm{Cd}-\mathrm{O}$ distances ranging from 2.26 to $2.59 \AA$, and its $\mathrm{CHI}$ function is almost identical with that of sample $C d-Y$.

A similar technique was applied to the second shell of $\mathrm{Cd}-\mathrm{Y}$ (IFT 2.3-3.8 $\AA$ ). PdO and CdS were used both isolated and combined as references for $\mathrm{Cd}-\mathrm{Cd}$ and $\mathrm{Cd}-\mathrm{Si}$ scatter pairs (see the Experimental Section). The best fit is shown in Figure 8B. The resulting values for bond distances, coordination numbers, and Debye-Waller factors of both shells were finally used for a fit of the whole data file (IFT, 1.3-3.8 $\AA$ ) and were refined to the values listed in Table III. The final fit of the CHI function and its Fourier transformation into $R$ space is shown in Figure 9.

The results as shown in Table III are interpreted in terms of a distorted cadmium oxide cube located in the sodalite cavities of the zeolite framework.

1. From the combined presence of oxygen in the first shell and $\mathrm{Si} / \mathrm{Al}$ neighbors in the second shell, it is clear that the $\mathrm{Cd}^{2+}$ ions are located in zeolite extra-framework cation positions. A Cd-O distance of $2.44 \AA$ is common for cations stabilized in the six-ring coordination sites of faujasites. A similar value $(2.48 \AA$ ) was also extracted from X-ray diffraction data in this work and was attributed to $\mathrm{Cd}$ in $\mathrm{SI}^{\prime}$ positions (Figure 6). In agreement with the $\mathrm{X}$-ray data, we can exclude the occupation of the SI sites by Cd(II) in double six-ring positions since the EXAFS data could not be fitted with a coordination distance of $2.6 \AA$, expected for this site.

2. Additional oxygen neighbors ( $\mathrm{SI}^{\prime}$ requires only three per $\mathrm{Cd}^{2+}$ ) were detected at relatively short distances of 2.25 , which is very close to values of $2.28 / 2.22 \AA$ found for $\mathrm{Cd}(1)-\mathrm{O}(5)$ in 

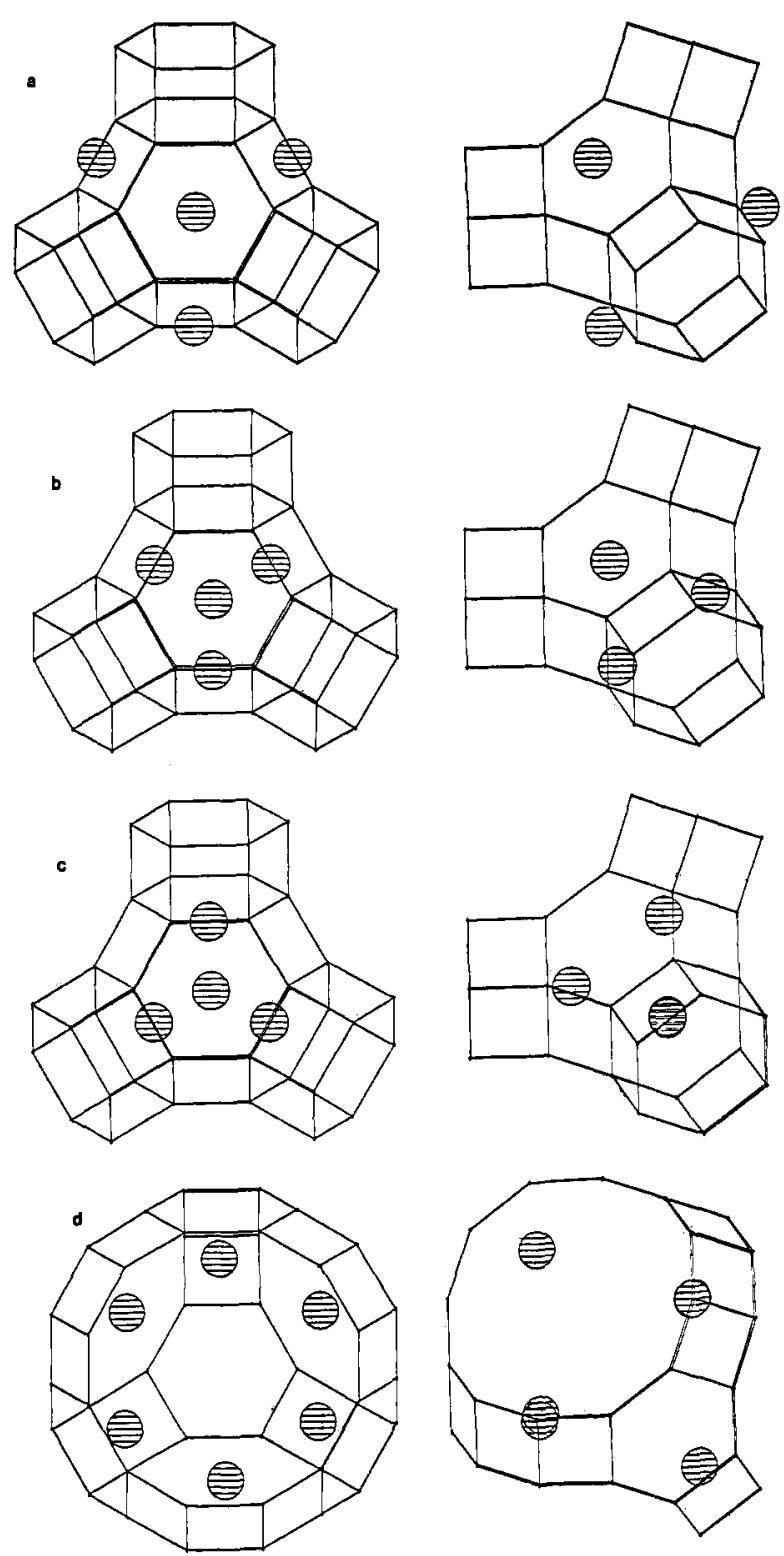

Figure 5. Extra-framework ion sites of zeolite $\mathrm{Y}$ shown as hatched circles. The framework is represented by sticks connecting the $T$ atoms and omitting the oxygen atoms: (a) view of sodalite cage illustrating the SII site, (b) view of sodalite cage illustrating the $\mathrm{SI}^{\prime}$ site, (c) view of sodalite cage illustrating the SII' site, (d) view of a supercage illustrating the SIII site.

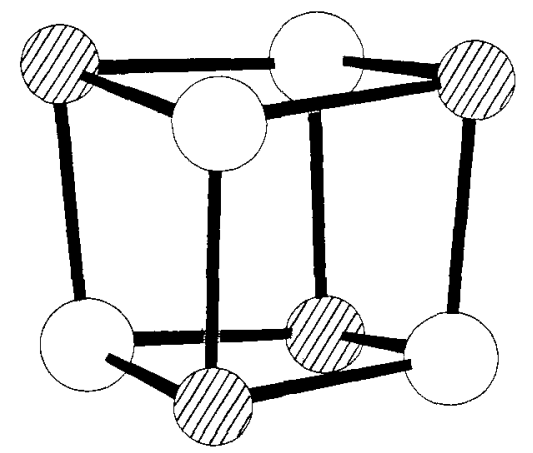

Figure 6. Structure of the $(\mathrm{CdS}, \mathrm{O})_{4}$ units located within the zeolite sodalite units (solid circles, $\mathrm{Cd}$; open circles, $\mathrm{S}(\mathrm{O})$ ).

samples CdS-Y 13 and CdS-Y 16 by XRD. We therefore assign this bond distance to $\mathrm{Cd}-\mathrm{OH}$ or $\mathrm{Cd}-\mathrm{H}_{2} \mathrm{O}$ with oxygen occupying SII' $^{\prime}$ sites in the sodalite cages.

3. A significant fraction of the second shell is due to $\mathrm{Cd}-\mathrm{Cd}$ scattering at $R=3.29 \AA$. A fit with a similar quality was also

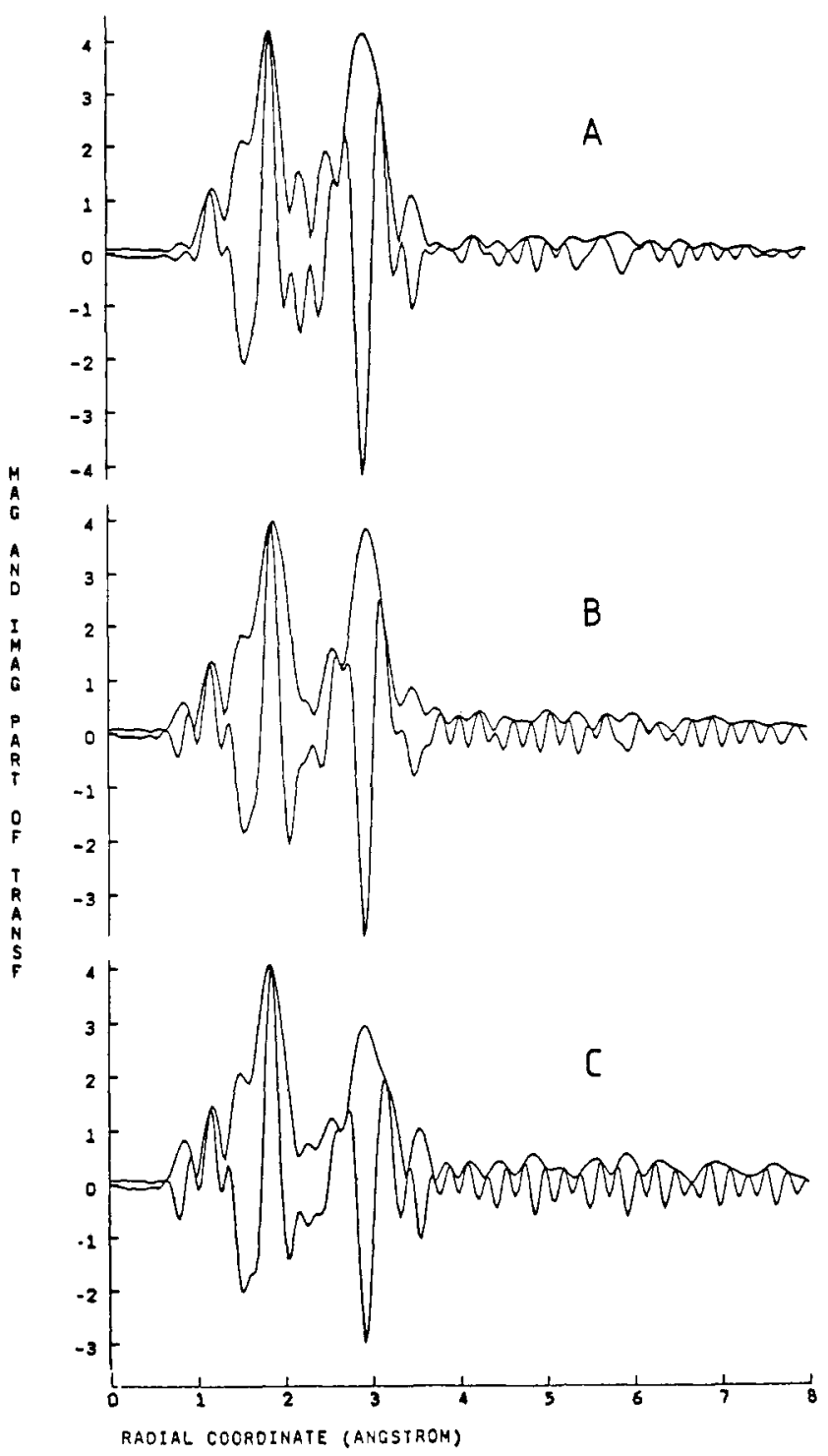

Figure 7. $k^{3}$ Fourier transformation of (A) Cd-Y, (B) CdS-Y 6, and (C) CdS-Y 16

obtained with the second shell solely composed of $\mathrm{Si} / \mathrm{Al}$ neighbors. The total number of $\mathrm{Cd}-\mathrm{Si} / \mathrm{Al}$ would then be higher than 12 (uncorrected). We can exclude this alternative because it would require that all $\mathrm{Cd}$ would reside in SI positions. A further indication for the presence of cadmium neighbors in the second shell is a positive peaking of the imaginary part in that shell if a phase correction for cadmium is applied. These results together point toward the formation of sodalite stabilized $\mathrm{Cd}_{4} \mathrm{O}_{4}$ cubes, where each $\mathrm{Cd}$ is coordinated to three zeolite oxygens $(\mathrm{OZ})$ and three extra-framework oxygens. Every Cd cation detects, in addition, three other $\mathrm{Cd}$ in its close neighborhood. The third $\mathrm{Cd}-\mathrm{O}$ distance at $2.34 \AA$ resembles those found for extra-framework oxygen coordinated to Cd in SIII sites in samples CdS-Y 13 and CdS-Y 16 by XRD. Therefore, some of the $\mathrm{Cd}$ ions are likely to be located at these sites.

A similar model based on a $\mathrm{Cd}_{4}\left(\mathrm{O}_{\mathrm{w}}\right)_{4}$ cube was proposed by Calligaris et al., ${ }^{33}$ who found $\mathrm{Cd}^{2+}$ in $\mathrm{SI}^{\prime}$ positions and $\mathrm{H}_{2} \mathrm{O}$ occupying SII' sites in a partially dehydrated $\mathrm{Cd}-\mathrm{Y}$ zeolite. The $\mathrm{Cd}$ bond distances to zeolite oxygen $(2.40 \AA)$ and to oxygen of zeolite water $(2.36 \AA)$ closely resemble our results. It appears

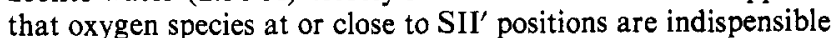
as shields of neighboring divalent cations located in SI'$^{\prime}$. A similar stabilizing effect of $\mathrm{OH}^{-}$has been proposed in an X-ray diffraction

(33) Calligaris, M.; Mardin, G.; Randaccio, L.; Zangrando, E. Zeolites 1986, 6,439 . 

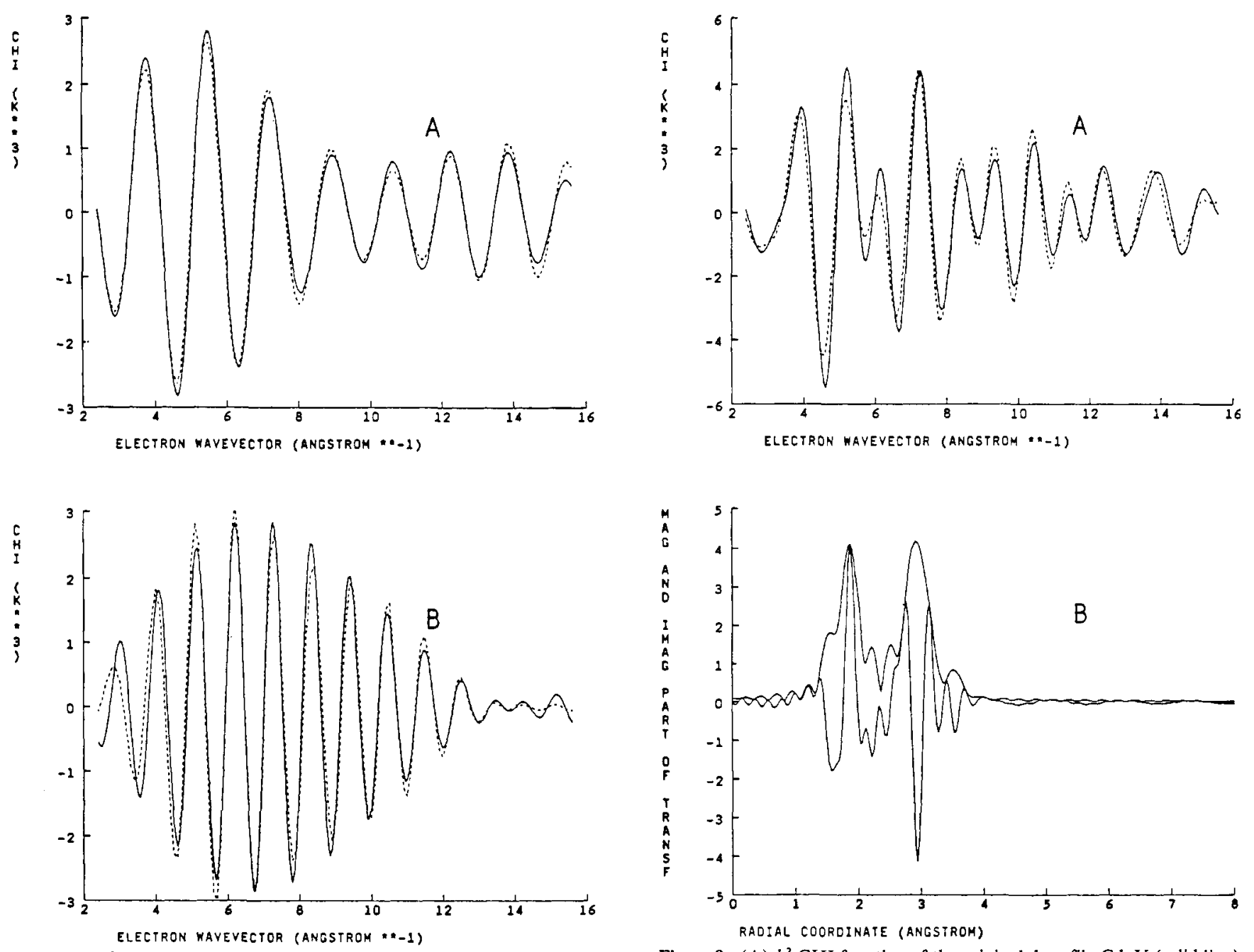

Figure 8. $k^{3}$ EXAFS modulation (solid line) and fit (broken line) of (A) first shell of $\mathrm{Cd}-\mathrm{Y}$ and (B) second shell of $\mathrm{Cd}-\mathrm{Y}$.

study of $\mathrm{Ca}$ faujasites. The data were consistent with a $\mathrm{Ca}^{+}-$ $(\mathrm{OH})_{2} \mathrm{Ca}^{+}$double hydroxide bridge arrangement $\left(\mathrm{Ca}\right.$ in $\mathrm{SI}^{\prime}, \mathrm{OH}$ in $\mathrm{SII}^{\prime}$ ), which represents a fragment of the $\mathrm{Cd}_{4} \mathrm{O}_{4}$ cube proposed in the present study. ${ }^{34}$ It should be noted that our results for $\mathrm{Cd}-\mathrm{O}$ and $\mathrm{Cd}-\mathrm{Cd}$ distances are very close to those of cubic $\mathrm{CdO}$ ( $\mathrm{NaCl}$ type) $\left(\mathrm{Cd}-\mathrm{O}, 2.35 \AA ; \mathrm{Cd}-\mathrm{Cd} 3.32 \AA^{35}\right.$ ). The intrazeolite $\mathrm{Cd}_{4} \mathrm{O}_{4}$ cube may therefore be considered as a small fraction of $\mathrm{CdO}$. Deviations in $\mathrm{N}$ found between the proposed cube model and the listed results, particularly for the $\mathrm{Cd}-\mathrm{Si}$ and $\mathrm{Cd}-\mathrm{Cd}$ scatter pairs, may result from the limited transferability of the available reference compounds.

Treatment of the cadmium-exchanged samples with $\mathrm{H}_{2} \mathrm{~S}$ at 100 ${ }^{\circ} \mathrm{C}$ causes only moderate changes in the overall appearance in the EXAFS spectrum (compare parts $\mathrm{A}$ and $\mathrm{B}$ of Figure 7). Changes between samples $\mathrm{Cd}-\mathrm{Y}$ and $\mathrm{CdS}-\mathrm{Y} 6$ are visible in the range of 1.9-2.4 $\AA$ (uncorrected), which have to be attributed to a new $\mathrm{Cd}-\mathrm{S}$ phase. Use of a difference-file technique allows us to detect and analyze this new contribution: in order to isolate this phase, the $\chi$ function of sample $\mathrm{Cd}-\mathrm{Y}$ was subtracted from that of sample CdS-Y 6, neglecting (as a first approximation) possible differences in the $\mathrm{Cd}-\mathrm{O}$ and $\mathrm{Cd}-\mathrm{Si}$ spheres. The major peak resembles the position and imaginary part of bulk $\mathrm{Cd}-\mathrm{S}$ (see Figure 10A; only the magnitude is shown for clarity). This difference file was fitted with CdS. The best fit results were used to calculate a $\mathrm{Cd}-\mathrm{S}$ contribution, which was subtracted from the original CdS-Y 6 data file. As shown in Figure 10B, the imaginary part is now very similar to that of $\mathrm{Cd}-\mathrm{Y}$. A fit of the entire data range resulted

(34) Costenoble, M. L.; Mortier, W. J.; Uytterhoeven, J. B. J. Chem. Soc., Faraday Trans. I 1978, 74, 466.

(35) Strukturberichte 1923/28, $1,72$.

Figure 9. (A) $k^{3} \mathrm{CHI}$ function of the original data file $\mathrm{Cd}-\mathrm{Y}$ (solid line) and fit (broken line). (B) $k^{3}$ Fourier transformation of the calculated EXAFS.

in values given in Table III. The reaction with $\mathrm{H}_{2} \mathrm{~S}$ causes a reduction of the total number of first-shell $\mathrm{Cd}-\mathrm{O}$ scatterers, while the second-shell values of $\mathrm{Cd}-\mathrm{Si} / \mathrm{Al}$ and $\mathrm{Cd}-\mathrm{Cd}$ are unchanged. We conclude that (1) the overall structure of the $C d$ arrangement in the zeolite is unchanged upon reaction with $\mathrm{H}_{2} \mathrm{~S}$ and (2) about half of the oxygens in the cube are replaced by sulfur. These results are consistent with the XRD data, and, beyond that, they indicate the presence of small, rather localized $(\mathrm{CdS}, \mathrm{O})_{4}$ units in the zeolite rather than extended chains with lower local coordination number. It is not clear at this point if the sulfur resides in the zeolite as $\mathrm{H}_{2} \mathrm{~S}$ or as $\mathrm{S}^{2-}$ (see below).

Sample CdS-Y 16 is distinguished from CdS-Y 6 by a strong decrease in the magnitude of the second shell. Consequently, the number of the $\mathrm{Si} / \mathrm{Al}$ and $\mathrm{Cd}$ neighbors is markedly reduced. Fit results presented in Table III show only $\mathrm{Si} / \mathrm{Al}$ scatterers listed; however, a small amount of $\mathrm{Cd}(N=<1)$ with concomitant reduction of $N$ for $\mathrm{Si} / \mathrm{Al}$ would result in a fit of comparable quality. Bond distances of the oxygen neighbors are close to sample $\mathrm{Cd}-\mathrm{Y}$, but the coordination numbers are considerably smaller. We suggest that in these samples the $\mathrm{Cd}^{2+}$ ions are still located in lattice coordination sites SI $^{\prime}$ and SIII. It seems that the cubes have been partially disrupted as indicated by the loss of strongly scattering $\mathrm{Cd}$ neighbors.

In conclusion, the EXAFS data show that the addition of $\mathrm{H}_{2} \mathrm{~S}$ to $\mathrm{Cd}^{2+}$-exchanged zeolites does not displace $\mathrm{Cd}$ from zeolite cation positions. Furthermore, the formation of bulklike $\mathrm{CdS}$ can certainly be ruled out by our EXAFS studies. It is shown that sulfur is located in the neighborhood of $\mathrm{Cd}$. It appears that the sulfur is incorporated into $\mathrm{Cd}_{4} \mathrm{O}_{4}$ cubes present in $\mathrm{Cd}$ exchanged and oxygen-treated samples. Since a total removal of intrazeolite water 

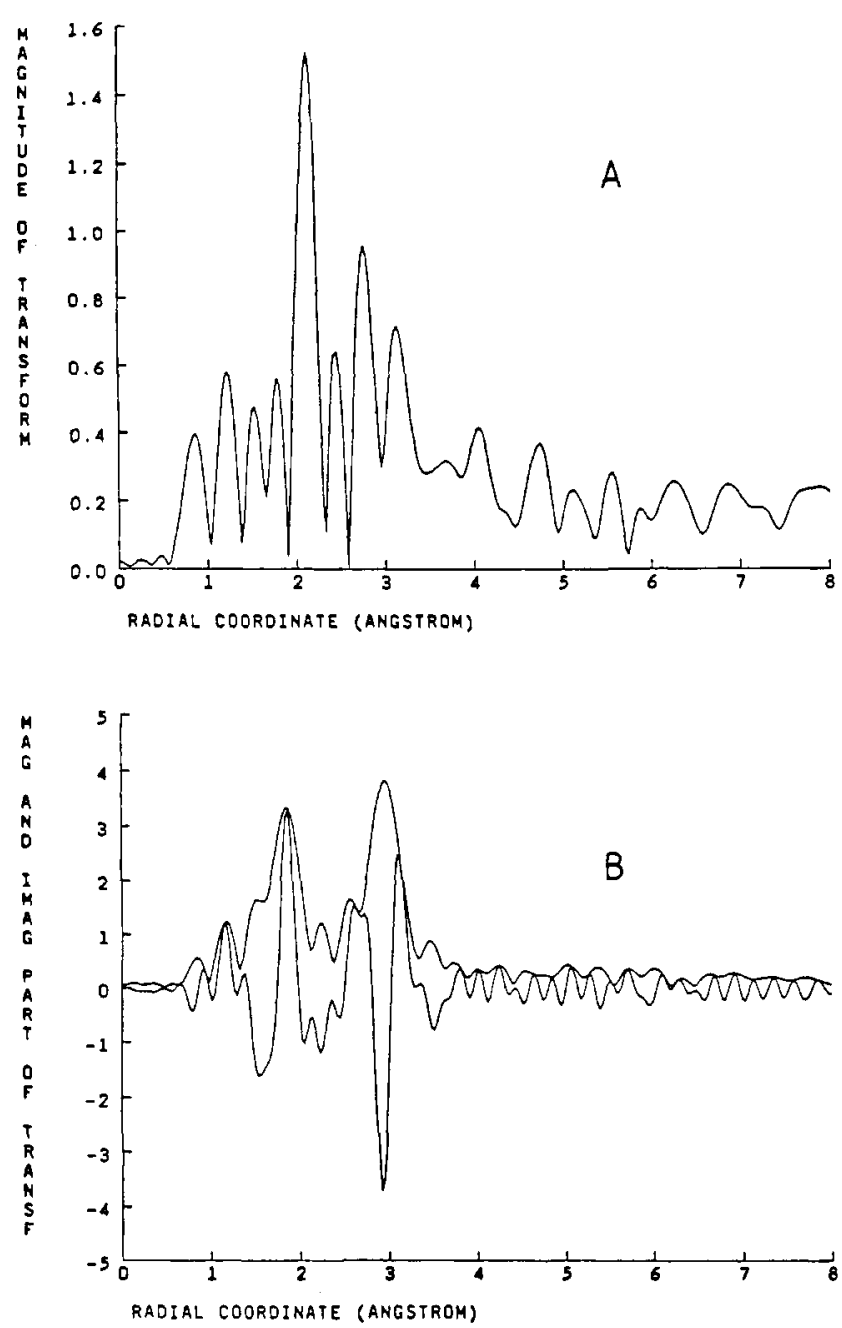

Figure 10. (A) $k^{3}$ Fourier transformation of the difference file of CdS-Y $6-\mathrm{Cd}-\mathrm{Y}$. (B) $k^{3}$ Fourier transformation of the difference file CdS-Y 6 minus a calculated contribution for sulfur $(R=2.52 \AA) N=1.5)$.

is difficult, the absolute amount of residual water may differ in our samples. The formation of $(\mathrm{CdS}, \mathrm{O})_{4}$ cubes appears to require the presence of donor ligands, e.g., $\mathrm{OH}^{-}$, water, sulfur, or zeolite framework species. Partial disruption of the cubes is indicated in the samples with a higher $\mathrm{Cd}$ loading. Similar results were obtained from a combined EXAFS, XRD study on CdSe loaded zeolites. ${ }^{36}$

\section{Discussion}

A. Why $(\mathrm{CdS}, \mathrm{O})_{4}$ Clusters Are So Stable inside the Sodalite Cages. The first thing to note from the $\mathrm{X}$-ray diffraction and EXAFS study is that all the $(\mathrm{CdS}, \mathrm{O})_{4}$ clusters reside in the smaller sodalite cages, not in the larger supercages. This initially surprising result can be immediately understood when one considers the stability of these cubic clusters. In a bare cubic cluster, every $\mathrm{Cd}$ atom is coordinatively unsaturated. The need to satisfy this unsaturation through rehybridization provides a tremendous driving force to break up the cube. The only way to have a stable cubic $(\mathrm{CdS}, \mathrm{O})_{4}$ cluster is to passivate the cube surface with the surrounding medium, in this case, the sodalite cages. Examination of the X-ray data reveals that every $\mathrm{Cd}$ atom is surrounded by three oxygen atoms of the six-ring windows of the sodalite cages (Figure 11). The $\mathrm{Cd}-\mathrm{O}$ distance, $2.48 \AA$, is somewhat larger than the typical $\mathrm{Cd}-\mathrm{O}$ bond length of $2.348 \AA{ }^{37}$ Four double six-ring windows, arranged in a tetrahedral symmetry, match

(36) Moller, K.; Eddy, M. M.; Stucky, G. D.; Herron, N.; Bein, T. J. Am Chem. Soc., in press.

(37) Landolt-Bornstein, New Series; Madelung, O., Ed.; Springer-Verlag: New York, 1983; Vol. 17b.

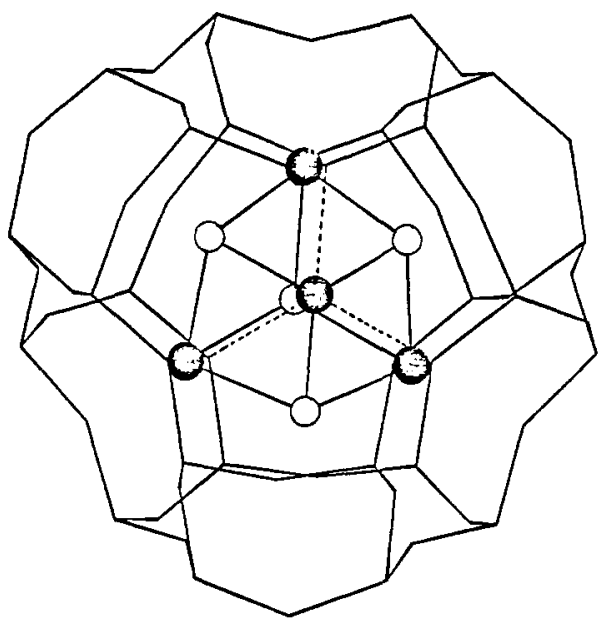

Figure 11. Representation of the $(\mathrm{CdS}, \mathrm{O})_{4}$ cube inside the sodalite unit where dotted lines emphasize the bonds between framework six-ring oxygen atoms (represented as points connected to $T$ atoms by sticks) and $\mathrm{Cd}$ atoms of the cluster (solid circles, $\mathrm{Cd}$; open circles, $\mathrm{S}(\mathrm{O})$ )

perfectly with four tetrahedrally arranged Cd atoms of the cube. The saturation of $\mathrm{Cd}$ coordination requirements by the framework oxygen atoms in the sodalite units is therefore the primary mechanism for the stability of $(\mathrm{CdS}, \mathrm{O})_{4}$ clusters. In the 13supercage, only one $\mathrm{Cd}$ atom of a cube could coordinate with the framework oxygens. This explains the instability and the absence of $(\mathrm{CdS}, \mathrm{O})_{4}$ cubes in the supercages. Our result also suggests that larger size CdS clusters should be stable in the supercage. At present, with the ion-exchange method the highest CdS loading that can be achieved is $23 \mathrm{wt} \%$, which just about fills the sodalite units. In order to fill up the supercages, different synthetic approaches are needed.

The stabilizing role of oxygen atoms in zeolites may not be unique. We note that most of the media used for preparing II-VI and IV-VI semiconductor particles, such a polymers, ${ }^{15,16}$ glasses, ${ }^{13,14}$ water, and alcohols, ${ }^{4-12}$ all contain oxygen atoms. Their presence may serve a purpose, namely, to passivate the particle surface.

B. From Clusters to Superclusters. X-ray diffraction data of low-loading sample CdS-Y 13 shows that Cd atoms are located at the four $\mathrm{SI}^{\prime}$ ion-exchange sites (Figure 5B). Due to the low loading level, it is possible that these SI' $^{\prime}$ sites are only partially occupied by $\mathrm{Cd}$. The exact location of the $\mathrm{Cd}$ atom among the four SI' sites cannot be determined by X-ray since they are all equivalent. Therefore, we can only assign the observed spectrum to $(\mathrm{CdS})_{1-4}$ clusters. Because of the enhanced stability of (CdS, O) ${ }_{4}$ inside the sodalite cage and the known instability of $\mathrm{CdS}$ molecule, ${ }^{38}$ we believe that $(\mathrm{CdS})_{4}$ is the more likely species present. This conclusion is supported by the EXAFS data discussed above. We also note that $\mathrm{H}_{2} \mathrm{~S}$-loaded zeolite has an absorption band in the $280-\mathrm{nm}$ region, which can interfere with the CdS cluster spectrum. ${ }^{39}$ We have observed abnormally strong absorption in the 280-nm region when the CdS zeolite sample has an excessively large $\mathrm{S} / \mathrm{Cd}$ ratio, which we believe is due to the presence of $\mathrm{H}_{2} \mathrm{~S}$. The spectrum reported here at low loading level comes from a sample with an excellent $1: 1 \mathrm{Cd} / \mathrm{S}$ ratio.

Once the CdS loading level exceeds the critical threshold of $4 \pm 1 \mathrm{wt} \%$, the absorption spectra shift to the red and become independent of the CdS concentration, up to the highest loading level that can be achieved by the ion-exchange method (see Figure 2). The absorption spectrum contains a shoulder near 350-360 $\mathrm{nm}$, most likely due to the exciton transition. Colloidal CdS particles with sizes of $25-30 \AA$ show a similar absorption spec. trum. ${ }^{6 c}$ Interestingly, the critical threshold concentration of $4 \pm$

(38) Many previous attempts to prepare and study the spectrum of CdS molecules in gas phase have failed due to their extreme instability. See: Huber, K. P.; Herzberg, G. Constants of Diatomic Molecules; Van Nostrand Reinhold: New York, 1979.

(39) Karge, H. G.; Ziolek, M.; Laniecki, M. Zeolites 1987, 7, 197. 

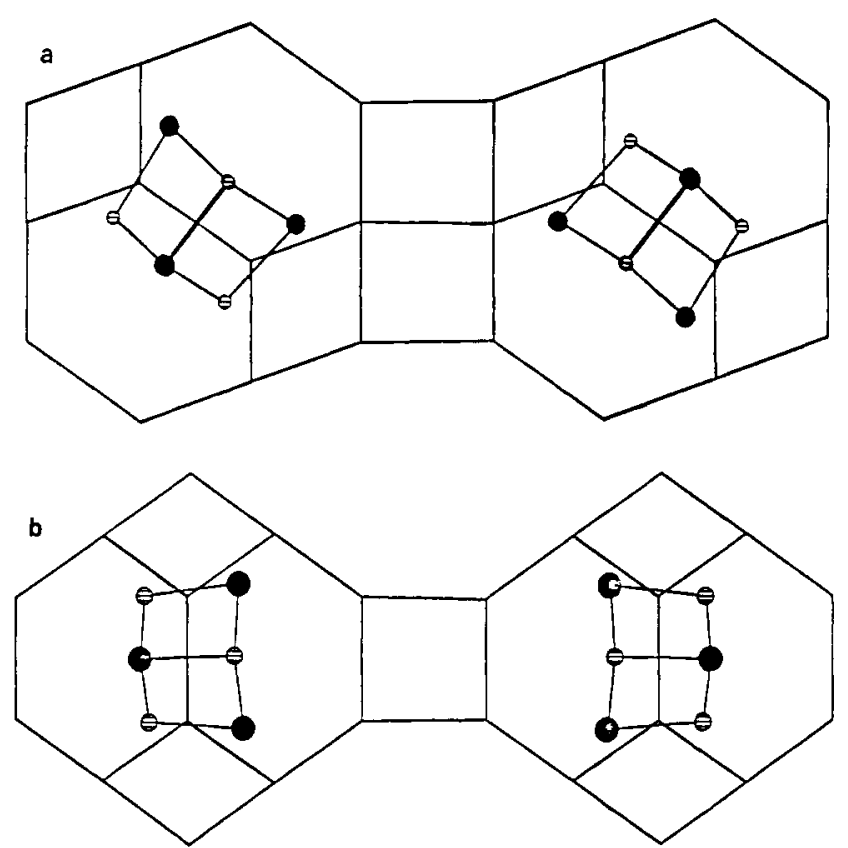

Figure 12. Relative orientation of two $(\mathrm{CdS}, \mathrm{O})_{4}$ clusters in adjacent sodalite units of (a) the $Y$ structure separated by a double six-ring linkage (solid circles, $\mathrm{Cd}$; open circles, $\mathrm{S}(\mathrm{O})$; cubes are viewed edge-on) and (b) the A structure separated by a double four-ring.

$1 \mathrm{wt} \%$ corresponds to the concentration at which, statistically, CdS clusters must now populate adjacent sodalite units. The rather abrupt transition further suggests that the cluster aggregation process may be percolative. For a three-dimensional percolation process, the percolation threshold is predicted to be around $15 \mathrm{vol} \% .^{31}$ If we consider the total free volume of zeolite $\mathrm{Y}(0.48 \mathrm{~mL} / 1 \mathrm{~mL}$ of zeolite $)$, then $4 \mathrm{wt} \% \mathrm{CdS}$ corresponds to only $2.3 \%$ by volume based on bulk density of CdS $(4.82 \mathrm{~g} / \mathrm{mL})$. However, X-ray study shows that all of the CdS clusters reside in the sodalite units and become unstable in the supercages, which suggests that only the free volume of the sodalite cages should be considered $(0.08 \mathrm{~mL} / 1 \mathrm{~mL}$ of zeolite). In this case, $4 \mathrm{wt} \%$ CdS corresponds to $14 \mathrm{vol} \%$, in excellent agreement with the percolation theory.

A coherent picture emerges from the X-ray and optical data in which isolated $(\mathrm{CdS}, \mathrm{O})_{4}$ clusters exist at low loading levels but percolate to form large superclusters at high loading levels. It is important to realize that in a supercluster each individual $(\mathrm{CdS}, \mathrm{O})_{4}$ cluster interacts with the other electronically through the sodalite cage windows (we will discuss the interaction mechanism in the next section). This is analogous to the much studied superlattice structure in solid-state physics ${ }^{40}$ where thin layers of semiconductor are separated by, and interact through, thin layers of a different semiconductor. Semiconductor-loaded zeolites therefore represent a three-dimensional analogue of the superlattice structure where the spatial arrangement of the semiconductor clusters is controlled by the zeolite host framework structure. When different zeolites are used as the template, superclusters (or superlattice) with different three-dimensional structures and electronic properties can be designed and built.

We also note that if one can simply fill up all the supercages in zeolite $\mathrm{Y}$, then a different supercluster is generated that has different structure and optical properties from the ones reported here. We estimate this should occur at about $35 \mathrm{wt} \% \mathrm{CdS}$ loading level, which, unfortunately, cannot be achieved with the currently used ion-exchange method.

C. Possible Interaction Mechanism within Superclusters. We now discuss the possible interaction mechanism between cubic $(\mathrm{CdS}, \mathrm{O})_{4}$ clusters within a supercluster. In zeolite $\mathrm{Y}$, two $(\mathrm{CdS}$, $\mathrm{O})_{4}$ clusters are separated by a double six-ring window ( $3-\AA$ width)

(40) Thin Films: Preparation and Properties; Tu, K. N., Rosenberg, R., Eds.; Academic: New York, 1983.

of the sodalite unit (Figure 12a). The two cubes point at each other through the $\mathrm{Cd}$ atoms at the vertices, the $\mathrm{Cd}-\mathrm{Cd}$ distance being $\sim 6 \AA$. This is too long a distance for direct interaction through space (i.e. too long for direct overlap of the wave functions). The only other alternatives for such a long-range interaction are (1) through the zeolite framework or (2) through bonding with species trapped inside the double six-ring window, such as $\mathrm{Cd}$ or $\mathrm{S}$. Thorough examination of the X-ray data shows that the electron density inside the double six-ring window is very low. This eliminates the possibility that either $\mathrm{Cd}$ or $\mathrm{S}$ is trapped inside the window. Interaction through the zeolite framework thus remains the most likely mechanism.

Through-bond interaction is a well-established concept used to describe long-range interaction between orbitals that are connected by $\sigma$ bonds ${ }^{41,42}$ Most of the studies involve C-C $\sigma$ bonds as the intervening orbitals. It has been shown that (1) through-bond interaction can extend over very long distance (up to six $\sigma$ bonds have been demonstrated ${ }^{42}$ ) and (2) through-bond interaction is sensitive to the conformation of the molecule. For example, in dehydropolyenyl, strong through-bond coupling exists only when the radical lobes and the carbon chain are in trans conformation; cis conformation gives weak interaction. ${ }^{41}$

To apply the through-bond interaction concept to CdS in zeolite, we view the six-membered ring windows of the sodalite units as the intervening bridges. Adjacent $(\mathrm{CdS}, \mathrm{O})_{4}$ clusters interact through these $\mathrm{Cd}-\mathrm{O}-\mathrm{Al}-\mathrm{O}-\mathrm{Si}-\mathrm{O}-\mathrm{Cd}$ bridges, which contain six $\sigma$ bonds. Such interaction is possible because of the strong coupling between $\mathrm{Cd}$ and $\mathrm{O}$ atoms as revealed by X-ray or EXAFS and pointed out in section IV.A. For zeolite $Y$ there are a total of six such bridges for interaction. The existence of six bridges should be especially effective in promoting the through-bond interaction since the interacting orbitals can have greater flexibility in choosing the bridge with the right conformation for interaction. The effectiveness of $\mathrm{O}-\mathrm{Al}-\mathrm{O}-\mathrm{Si}-\mathrm{O}$ bridges compared to the commonly studied $\mathrm{C}-\mathrm{C}$ bridge is unknown. A recent study ${ }^{43}$ shows that an $\mathrm{Si}-\mathrm{Si}$ bond is more effective than a $\mathrm{C}-\mathrm{C}$ bond in promoting the through-bond interaction.

It is also interesting to note that not only the adjacent cubes can interact through the $\mathrm{O}-\mathrm{Al}-\mathrm{O}-\mathrm{Si}-\mathrm{O}$ bridges, but $\mathrm{Cd}$ atoms in the same cube can also interact with each other through the same bridge. We believe this through-bond interaction between and within the cubes provides the "glue" for stabilizing the $\mathrm{CdS}$ supercluster. If we take $290 \mathrm{~nm}$ as the absorption edge of an isolated cluster and $350 \mathrm{~nm}$ as that of the supercluster, then the strength of the through-bond interaction is estimated to be about $0.7 \mathrm{eV}$, which is consistent with the known values of through-bond interaction..$^{41,42}$

The X-ray and optical data presented above indicate that CdS clusters can interact through the zeolite framework to form an extended supercluster structure. This suggests that different types of superclusters can be built with the same $(\mathrm{CdS}, \mathrm{O})_{4}$ building block by using different zeolites as the templates. An ideal candidate to demonstrate this principle is zeolite $A$, which is distinctly different in construction from $Y$ in that here the sodalite units are linked together via double four-rings in a cubic array (Figure 12b). In zeolite $\mathrm{A}$, the clusters in the neighboring sodalite units are expected to face each other through the facets of the cube separated by $\sim 9 \AA$, instead of the vertices as in zeolite $Y$ (Figure 12a). Preliminary results show the exciton shoulder of a CdS supercluster in zeolite $A$ is now located near $320 \mathrm{~nm}$, instead of $350 \mathrm{~nm}$ observed for $\mathrm{CdS}$ in zeolite $\mathrm{Y}$. If the structure of $\mathrm{CdS}$ clusters in zeolite $\mathrm{A}$ is the same as in $\mathrm{Y}$ (we have no reason to believe otherwise), then the data shows a very interesting orientational effect on the optical properties of CdS superclusters. Further studies, including structure determination using synchrotron X-ray diffraction, are in progress and will be published when competed.

(41) Hoffmann, R.; Imamura, A.; Hehre, W. J. J. Am. Chem. Soc. 1968 90,1499

(42) Paddon-Row, M. N. Acc. Chem. Res. 1982, 15, 245. 475 . 
D. Spectral Broadening Mechanisms. It is important to realize that although the size of the CdS cluster in zeolite is well-defined, i.e. a cube, the size of the supercluster is not. In an ideal situation, if one fills up all the sodalite cages with CdS, then the size of the supercluster is equivalent to the size of the bulk zeolite crystals. In reality, the ion-exchange method cannot totally fill up the sodalite cages. In addition, a high density of defects (usually extra Cd) and disorder exists with the current preparation procedures. These partial vacancies and imperfections break up the supercluster and introduce inhomogeneity in the supercluster size distribution, which is the primary reason for the broad exciton absorption peak that we observe. From the low-temperature excitation spectrum of $\mathrm{CdS}$ supercluster in zeolite $13 \mathrm{X}$ (Figure 3 ), the exciton width is about $3000 \mathrm{~cm}^{-1}$ at $4 \mathrm{~K}$. This is much broader than one would expect from a perfect supercluster.

Broadening due to size distribution of the supercluster can eventually be eliminated by improved synthetic procedures, as will be discussed in section IV.F. An intrinsic mechanism that cannot be eliminated is the phonon broadening. As the semiconductor particle size decreases, the coupling of electronic transition to surface and host phonons, especially high-frequency ones, becomes important. This gives rise to multiphonon sidebands and spectral broadening. We note that one of the novel features of CdS superclusters in zeolites is that every CdS in the supercluster is on the "surface". Strong coupling with the host lattice occurs through the interaction between $\mathrm{Cd}$ and framework oxygen. One would therefore expect the phonon coupling mechanism to become very effective. In a subsequent paper on the photophysical properties of CdS superclusters, we will present experimental data to demonstrate these points.

E. Effects of the Environment. It is clear from the above discussion that interaction with framework oxygen is necessary to stabilize the $(\mathrm{CdS}, \mathrm{O})_{4}$ clusters. It is then interesting to ask what effect this interaction has on the optical properties of such clusters. In principle, the optical properties of very small semiconductor particles can be modified through interaction with the surrounding environment; the extent of the modification depends on the strength of the interaction. In the extreme case of very strong interaction, the semiconductor itself can be destroyed. ${ }^{21}$ For example, we have shown that $\mathrm{CdS}$ is unstable in the presence of $\mathrm{H}_{2} \mathrm{~S}$, which reacts with $\mathrm{CdS}$ to form $\mathrm{Cd}(\mathrm{HS})_{2} \cdot{ }^{21}$ We believe that oxygen-containing media such as zeolites, glasses, polymers, and alcohols have relatively weak interaction with semiconductors such as $\mathrm{CdS}$ and $\mathrm{PbS}$, and the effects on their absorption spectra should be small. This is supported by the observation that the spectra of PbS in ethylene-15\% methacrylic acid copolymer film, in zeolite $\mathrm{Y}$, and in argon matrix are all very similar. ${ }^{16}$

Although the effects of zeolite framework on the CdS absorption spectrum may be small, its effects on the excited-state relaxation processes of CdS supercluster can be very large. This is analogous to the solvent effects on the photophysics of a molecule. Often the excited-state molecular relaxation processes are very sensitive to the solvent, while the absorption spectrum is only weakly perturbed by the presence of solvent.

F. Synthesis of Clusters and Superclusters. While the synthetic approach outlined in the Experimental Section is straightforward and leads to materials containing $\mathrm{CdS}$ as expected, the control of the $\mathrm{Cd} / \mathrm{S}$ stoichiometry presents considerable challenges. If one considers the chemistry involved in the formation of the CdS clusters (eq 5), it is clear that the reaction as written is readily

$$
\mathrm{Cd}^{2+} \mathrm{Zeol}^{2-}+\mathrm{H}_{2} \mathrm{~S} \leftrightarrow \mathrm{CdS}+2 \mathrm{H}^{+}+\mathrm{ZeOl}^{2-}
$$

reversible; i.e. while $\mathrm{CdS}$ is generated, the protons of the $\mathrm{H}_{2} \mathrm{~S}$ reagent become the zeolite charge compensators forcing the CdS clusters to reside in an extremely acidic environment. In such an environment $\mathrm{CdS}$ is unstable with respect to the dissociation into $\mathrm{Cd}$ ions and $\mathrm{H}_{2} \mathrm{~S}$. Therefore, the $\mathrm{CdS}$ content of the zeolite is dependent on the position of the equilibrium in eq 5 and thus on the partial pressure of $\mathrm{H}_{2} \mathrm{~S}$ present. We find that, as a result, it is possible to simply pump on the CdS-loaded zeolite and remove all of the sulfur to return to a $\mathrm{Cd}$ zeolite given sufficient time.
We believe that equilibrium (eq 5 ) is the basic reason for the breaking up of superclusters and the presence of defects. One way to improve the quality of the supercluster is to monitor the $\mathrm{Cd} / \mathrm{S}$ ratio in situ during the growth process and to find optimal growth conditions such as temperature, flow rate, etc. In essence, one needs the kind of precise control that are characteristic of modern epitaxial growth techniques. With respect to the in situ monitoring of $\mathrm{Cd} / \mathrm{S}$ ratio, we have done thermogravimetric analysis of a sample loaded with a 5-fold excess of $\mathrm{H}_{2} \mathrm{~S}$ over that necessary to completely convert all $\mathrm{Cd}$ sites to $\mathrm{CdS}$. The data shows that all $\mathrm{H}_{2} \mathrm{~S}$ is removed smoothly by flushing with nitrogen so that no break in the weight loss curve corresponding to the $1: 1$ $\mathrm{Cd} / \mathrm{S}$ stoichiometry is apparent. This makes the monitoring and control of $\mathrm{Cd} / \mathrm{S}$ ratio difficult and an empirical approach is more or less needed.

To avoid the problems associated with equilibrium (eq 5) and to bypass the inherent limitation of the ion-exchange method in terms of loading capability, alternative organometallic synthetic routes may be needed. As we mentioned before, a major reason for the inhomogeneity of supercluster size distribution is due to the partial vacancy of the sodalite cages, which in turn originates from the limited ion-exchange capability of zeolites. With zeolite $13 \mathrm{X}$, which has the highest ion-exchange capability, the highest CdS loading achieved is $25 \mathrm{wt} \%$, which is close to the $27 \mathrm{wt} \%$ level needed for full occupancy of all sodalite cages. An organometallic route is also necessary if one wants to fill up the supercages, which would yield superclusters with totally different structures and electronic properties. We are currently exploring these alternative approaches.

\section{Summary}

Well-defined CdS clusters and superclusters have been synthesized within the pore structure of zeolite $Y$. At low CdS loading density, discrete $(\mathrm{CdS}, \mathrm{O})_{4}$ clusters are formed inside the sodalite cages. Their absorption spectra have a shoulder near $290 \mathrm{~nm}$. At high loading density, discrete $(\mathrm{CdS}, \mathrm{O})_{4}$ cubes begin to interconnect to form an imperfect supercluster (or superlattice) structure. The absorption spectrum of the supercluster has a shoulder near $350 \mathrm{~nm}$. The discrete cube building blocks consist of interlocking tetrahedra of $\mathrm{Cd}$ and $\mathrm{S}$ with a $\mathrm{Cd}-\mathrm{S}$ bond length of $2.47 \AA$. A supercluster then consists of many such interconnected cubes with spatial geometry defined by that of the sodalite units. In zeolite $Y$, cubes in the adjacent sodalite units have $C d$ atoms pointing toward each other through the double six-ring window with a $\mathrm{Cd}-\mathrm{Cd}$ distance of $\sim 6 \AA$.

The unique stability of $(\mathrm{CdS}, \mathrm{O})_{4}$ clusters inside the sodalite units is due to the coordination of Cd atoms with the framework oxygen atoms of the double six-ring windows. The stability of the supercluster comes from the interaction between (CdS) clusters in the adjacent sodalite units. We suggest that through-bond coupling is responsible for the interaction between clusters.

Semiconductor superclusters represent a novel class of materials where the three-dimensional structure and electronic properties can be controlled by using different zeolites as the template. Imperfections do exist with these materials at present, in particular, the lower than ideal occupancy of the sodalite units. Alternative synthetic routes and better control in fabrication processes need to be explored in the future. Large single-crystal zeolites are required for exploring the optoelectronic properties.

Acknowledgment. We thank J. B. Jensen and S. H. Harvey for their excellent technical assistance. We are indebted to $P$. E. Bierstedt for XPS analysis and J. E. MacDougall for sample preparations. G.D.S. acknowledges support of this research by the Office of Naval Research under Grant N00014-87-K-0457. K.M. and T.B. acknowledge partial support by the SandiaUniversity Research Program (DOE). The operational fund for NSLS beam-line X-11A is supported by DOE Grant DEAS0580ER10742.

Registry No. $\mathrm{H}_{2} \mathrm{~S}, 7783-06-4 ; \mathrm{Cd}\left(\mathrm{NO}_{3}\right)_{2}, 10325-94-7$. 